Universidad de Lima

Facultad de Ciencias Empresariales y Económicas

Carrera de Administración

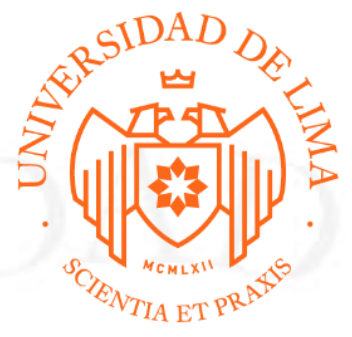

\title{
CASO DE ESTUDIO: ANÁLISIS Y DIAGNÓSTICO DE UNA EMPRESA DEL SECTOR AGROINDUSTRIAL PERUANO, PROPUESTA DE UN PLAN ESTRATÉGICO
}

Trabajo de suficiencia profesional para optar el Título Profesional de Licenciado en Administración

\section{Alex Raul Camargo Tolentino \\ Código 20121555}

$$
\text { Lima - Perú }
$$

Noviembre de 2019 
CASE STUDY: ANALYSIS AND DIAGNOSE OF A COMPANY FROM THE PERUVIAN AGRIBUSINESS SECTOR, A STRATEGIC PROPOSAL 


\section{TABLA DE CONTENIDO}

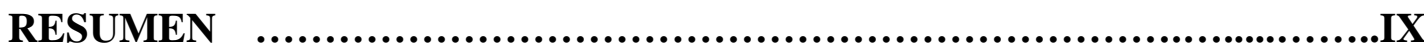

ABSTRACT

INTRODUCCIÓN......................................................................1

CAPÍTULO I: DIAGNÓSTICO ESTRATÉGICO.....................................2

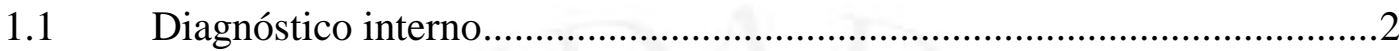

1.1.1 Análisis del modelo de negocio ..........................................................2

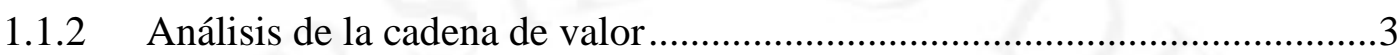

1.1.3 Definición y sustentación de las ventajas competitivas de la empresa y por

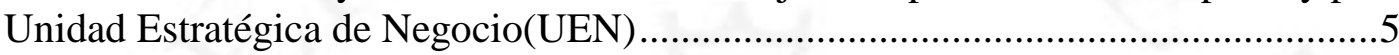

1.1.4 Determinación y sustentación de las Fortalezas y Debilidades de la empresa y por Unidad Estratégica de Negocio(UEN) .................................................... 8

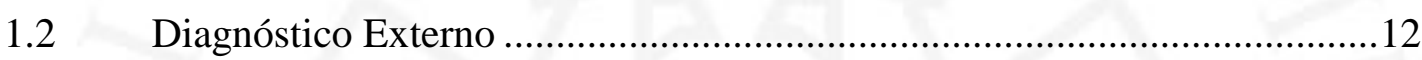

1.2.1 Análisis PEST (Sustentación de las fuerzas en base a la evolución futura de

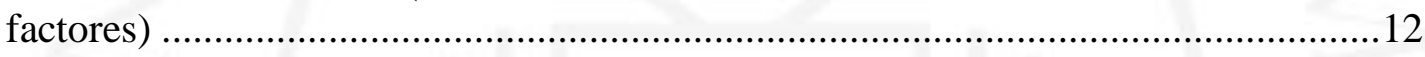

1.2.2 Análisis de las fuerzas competitivas del sector ..........................................15

1.2.3 Determinación y sustentación de Oportunidades y Amenazas .....................18

CAPÍTULO II: FORMULACIÓN DE LA ESTRATEGIA.....................22

2.1 Desarrollo y sustentación de la Matriz EFI ..............................................22

2.2 Desarrollo y sustentación de la matriz EFE..............................................23

2.3 Matriz de la Estrategias Genéricas (Sustento) ...........................................24

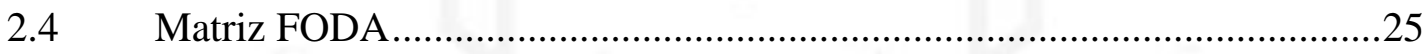

2.5 Definición y sustentación de la Visión, Misión y Políticas ..........................27

2.6 Definición de los Objetivos Estratégicos de la empresa............................28

2.7 Redefinición de las Unidades Estratégicas de Negocio(UEN) o creación de

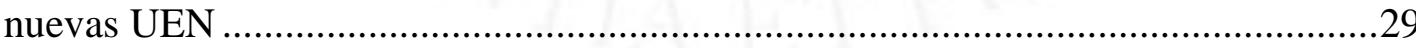

2.8 Propuesta y sustentación de estrategias en el ambiente Global, Corporativas de

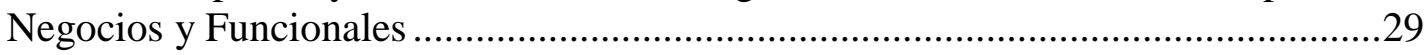

CAPÍTULO III: IMPLEMENTACIÓN ESTRATÉGICA.......................32

3.1 Evaluación del rediseño o no rediseño de la estructura organizacional de la

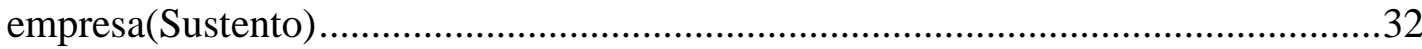

3.2 Propuesta de cambios para mejorar la implementación de estrategias en la empresa................................................................. 33

CAPÍTULO IV: CONTROL ESTRATÉGICO................................34 
4.1 Diseño de un Mapa Estratégico de Control para la empresa ........................34

4.2 Desarrollo de un Cuadro de Mando Integral con un mínimo de diez índices de

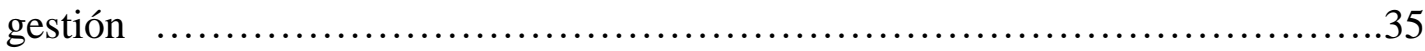

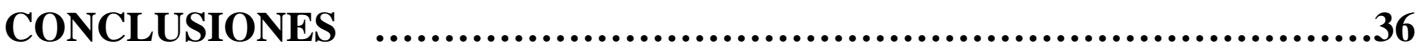

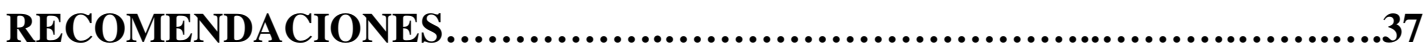

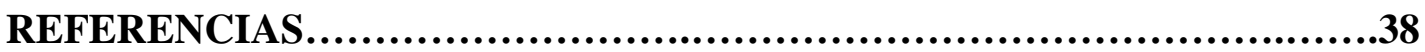

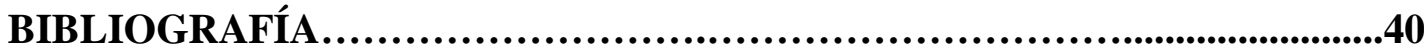

ANEXOS 


\section{ÍNDICE DE TABLAS}

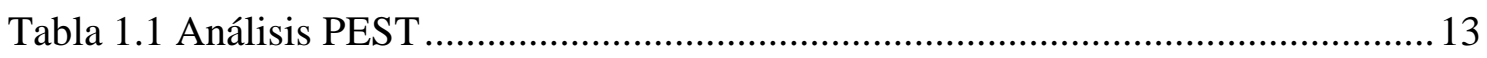

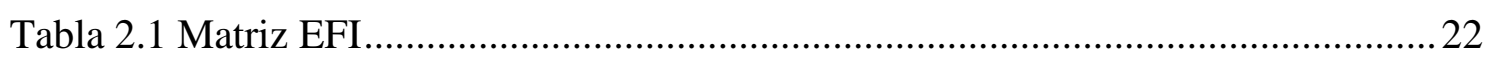

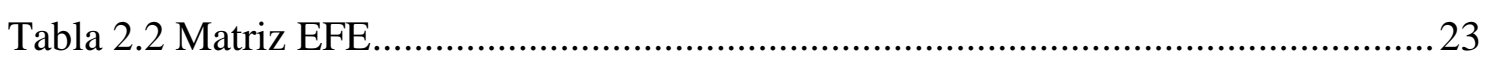

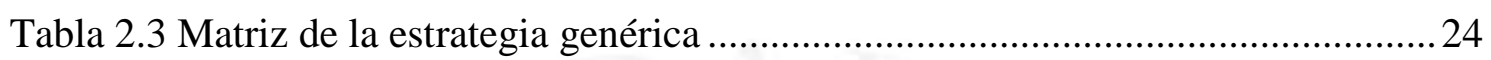

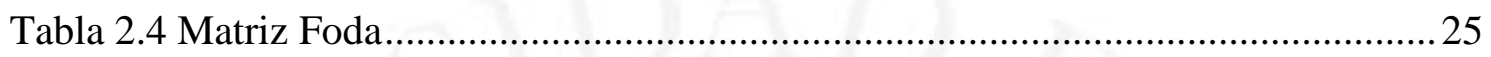

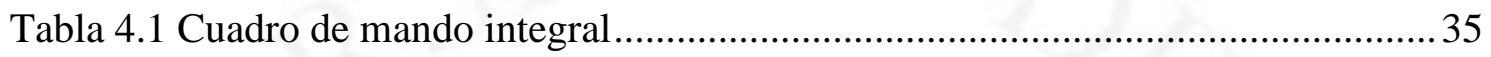




\section{ÍNDICE DE FIGURAS}

Figura 1.1 Análisis del modelo de negocio de Camposol............................................2

Figura 1.2 Cadena de Valor UEN Frutas y verduras ................................................... 3

Figura 1.3 Cadena de valor UEN Mariscos ........................................................... 4

Figura 1.4 Cadena de valor UEN Comercio .......................................................... 4

Figura 1.5 Participación de empresas exportadoras de arándanos................................ 15

Figura 1.6 Participación de empresas exportadoras de espárragos ............................... 16

Figura 1.7 Participación de empresas exportadoras de aguacates ................................ 16

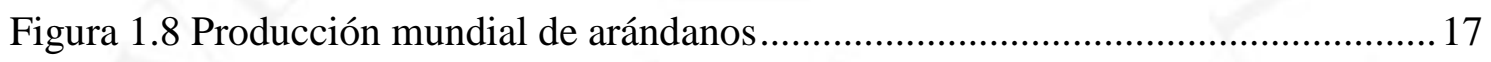

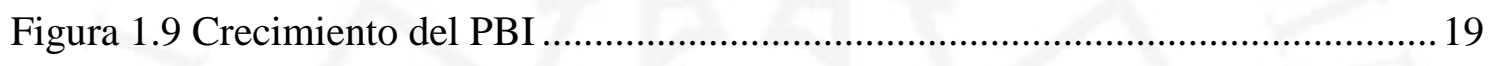

Figura 3.1 Estructura organizacional de Camposol .................................................. 32

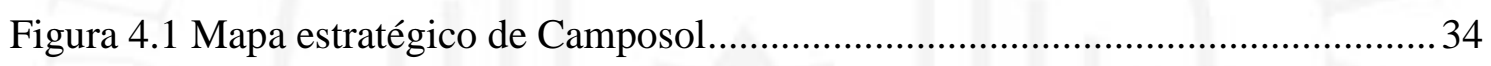




\section{ÍNDICE DE ANEXOS}

Anexo 1: Principales países exportadores de Arándanos

Anexo 2: Ventana de producción de Arándanos por países

43 


\section{RESUMEN}

El presente trabajo de suficiencia profesional se focaliza en el estudio de la empresa Camposol, empresa peruana del sector agroindustrial ubicada en el norte del Perú, se realiza un análisis estratégico interno de sus fortalezas y debilidades y externo de sus oportunidades y amenazas para determinar la situación actual de la compañía y plantear estrategias.

En el primer capítulo se realiza un diagnóstico estratégico interno y externo que permite conocer el modelo de negocio, la cadena de valor, las ventajas competitivas, las fortalezas y debilidades de cada UEN de la empresa Camposol, posterior a ello se realiza un análisis externo de la compañía para determinar las oportunidades y amenazas del entorno.

En el segundo capítulo se formulan las estrategias en base a las matrices EFI, EFE, FODA, lo cual permiten a través de la contratación de factores el planteo de las estrategias a seguir para Camposol.

En el tercer capítulo, se propone el rediseño de la estructura organizacional para Camposol y se proponen ciertos cambios para la implementación de las estrategias en la empresa.

Por último, en el cuarto capítulo, se propone un mapa estratégico de control base para la creación de un cuadro de mando integral con indicadores de gestión cuantificables y medibles en el transcurso del tiempo.

Palabras clave: Camposol, Agroindustria, arándanos, cadena de valor, análisis estratégico. 


\begin{abstract}
The present work of professional sufficiency focuses on the study of the company Camposol, a Peruvian company in the agroindustry sector located in northern Peru, an internal strategic analysis of its strengths and weakness and external strategic of its opportunities and threats is made to determine the current situation of the company and propose strategies.

In the first chapter an internal and external strategic diagnosis is made that allows to know the business model, the value chain, the competitive advantages, the strengths and weaknesses of each SBU of the Camposol company, after this an external analysis of the company is made to determine the opportunities and challenges of the environment

In the second chapter, the strategies are formulated based on the EFI, EFE, SWOT matrices, which allows, through the contrast of factors, to propose the strategies to be followed for Camposol.

In the third chapter, the redesign of the organizational structure for Camposol is proposed and changes are proposed for the implementation of the strategies in the company.

Finally, in the fourth chapter, it proposes a strategic control base map for the creation of the balanced scorecard with quantifiable and measurable management indicators over time.
\end{abstract}

Keywords: Camposol, agroindustry, blueberries, value chain, strategic analysis. 


\section{INTRODUCCIÓN}

Camposol es una empresa agroindustrial peruana, inicio sus operaciones en el año 1997 en la región La Libertad, iniciando sus operaciones con el espárrago centrando todos sus esfuerzos en dicho producto durante más de una década, cuya producción era dirigida principalmente hacia Europa, estuvo beneficiado del proyecto Chavimochic donde adquirieron tierras a través de una subasta pública, Chavimochic fue un proyecto que habilito de agua a la costa peruana.

En el año 2007 fue adquirida por D\&C Holding, grupo familiar peruano propietario de Copeinca, paso por un proceso de reestructuración, solicitando préstamos para la expansión de más hectáreas de cultivo.

Camposol para no depender de un solo producto amplio su portafolio de productos incluyendo cultivos como la palta, uva de mesa, arándano, entre otros. Siendo la palta el producto estrella por muchos años para Camposol.

En el año 2008, Camposol inicio ensayos experimentales con algunas variedades de arándanos, encontrando en el Biloxi la variedad con mejores características en tamaño, sabor y producción, se realizaron las primeras exportaciones en el año 2009 con una muy buena recepción por parte de los clientes, siendo ahora el producto principal de Camposol.

En la actualidad la empresa cuenta con más de 25,000 hectáreas de producción atiende a Estados Unidos, Europa y China a través de oficinas comerciales que le permiten tener una negoción más directa con los clientes. 


\section{CAPÍTULO I: DIAGNÓSTICO ESTRATÉGICO}

\subsection{Diagnóstico interno}

Según Luna (2014), El diagnóstico de una empresa es investigar cómo funciona la empresa en el presente y obtener información precisa para plantear las intervenciones del cambio (p. 4).

Por tal motivo se procederá a realizar el diagnóstico interno de la compañía para detectar la situación real de Camposol y que será el punto de partida para el planteamiento de las estrategias a seguir en el futuro.

\subsubsection{Análisis del modelo de negocio}

Para realizar el análisis de negocio de Camposol se usará el método propuesto por Osterwalder y Pigneur.

La mejor manera para describir un modelo de negocio es dividirlo en nueve módulos básicos que reflejen la lógica que sigue una empresa para obtener sus ingresos. Estos nueve módulos cubren las 4 áreas principales de un negocio: clientes, oferta, infraestructura y viabilidad económica. (Osterwalder y Pigneur, 2010, p. 15)

Figura 1.1

Análisis del modelo de negocio de Camposol

\begin{tabular}{|c|c|c|c|c|c|}
\hline Asociaciones Clave & Actividades Clave & Propuesta o & lor & Relaciones con los clientes & Segmento de Clientes \\
\hline $\begin{array}{l}\text { Estado Peruano, } \\
\text { accionistas, entidades } \\
\text { financieras que aportan } \\
\text { capital de préstamo para } \\
\text { la empresa y los distintos }\end{array}$ & $\begin{array}{l}\text { Laboratorio, cosecha } \\
\text { producción, empaquetado } \\
\text { y transporte de sus } \\
\text { productos. } \\
\text { Inversiones en I+D. }\end{array}$ & $\begin{array}{l}\text { Camposol ofr } \\
\text { productos de } \\
\text { con alto valor } \\
\text { asegura todal }\end{array}$ & $\begin{array}{l}\text { ece } \\
\text { alta calidad } \\
\text { nutritivo, } \\
\text { a cadena }\end{array}$ & $\begin{array}{l}\text { Camposol fideliza a sus clientes } \\
\text { a través de brindar productos } \\
\text { de alta calidad con certificaciones } \\
\text { y asegurando tratos comerciales } \\
\text { justos con los minoristas. }\end{array}$ & $\begin{array}{l}\text { Los clientes directos de } \\
\text { Camposol son los grandes } \\
\text { minoristas ubicados en } \\
\text { EU, Europa y China. }\end{array}$ \\
\hline $\begin{array}{l}\text { minoristas con los cuales } \\
\text { tienen acuerdos } \\
\text { comerciales. }\end{array}$ & $\begin{array}{l}\text { Recursos Clave } \\
\text { En recursos físicos posee } \\
\text { más de } 5000 \text { ha de cultivo } \\
\text { capital humano y } \\
\text { las fuentes de } \\
\text { financiamiento. }\end{array}$ & $\begin{array}{l}\text { de valor desd } \\
\text { laboratorio ha } \\
\text { directa a sus c } \\
\text { a nivel intern }\end{array}$ & $\begin{array}{l}\text { e el } \\
\text { asta la venta } \\
\text { dientes } \\
\text { acional. }\end{array}$ & $\begin{array}{l}\text { Canales } \\
\text { Camposol realiza ventas directas } \\
\text { a los minoristas, eliminando } \\
\text { intermediarios y asegurando que } \\
\text { sus productos lleguen en óptimas } \\
\text { condiciones al cliente final. }\end{array}$ & $\begin{array}{l}\text { Los clientes fianles son } \\
\text { personas interesadas en } \\
\text { adquirir productos } \\
\text { saludables de alto } \\
\text { valor nutritivo. }\end{array}$ \\
\hline $\begin{array}{l}\text { Estructura de Costes } \\
\text { Insumos para la cosecha } \\
\text { pago de mano de obra, }\end{array}$ & $\begin{array}{l}\text { e los distintos productos } \\
\text { antenimiento de las instal }\end{array}$ & $\begin{array}{l}\text { poseen, } \\
\text { nes y costo }\end{array}$ & $\begin{array}{l}\text { Venta dir } \\
\text { en Miami }\end{array}$ & $\begin{array}{l}\text { ngresos } \\
\text { a a los minoristas a través de of } \\
\text { otterdam y Shangai, }\end{array}$ & inas comerciales ubicadas \\
\hline
\end{tabular}

Fuente: Bell, D.E., y Kindred, N.(2016), Osterwalder, A. y Pigneur, Y. (2010)

Elaboración propia 


\subsubsection{Análisis de la cadena de valor}

Según Hitt, Ireland y Hoskisson (2015), El análisis de la cadena de valor permite a la compañía saber que partes de sus operaciones generan valor y cuáles no lo hacen (p. 89).

Se analizará la cadena de valor de cada Unidad estratégica de negocio (UEN) debido a que cada UEN presenta actividades distintas de acuerdo al producto que ofrecen y al cliente que está enfocado.

\section{- Cadena de Valor UEN Frutas y Verduras}

Figura 1.2

Cadena de Valor UEN Frutas y verduras

\begin{tabular}{|c|c|c|c|c|}
\hline \multicolumn{5}{|l|}{$\begin{array}{l}\text { INFRAESTRUCTURA } \\
\text { Laboratorios, campos }\end{array}$} \\
\hline \multicolumn{5}{|c|}{$\begin{array}{l}\text { RECURSOS HUMANOS } \\
\text { Camposol cuenta con más de 14,000 trabajdores en granjas y fabricas y más de 1,000 empleados } \\
\text { corporativos, siendo uno de los mayores empleadores del Perú }\end{array}$} \\
\hline \multicolumn{5}{|c|}{$\begin{array}{l}\text { DESARROLLO DE TECNOLOGIA } \\
\text { Posee una fuerte inversión en I+D de nuevos cultivos y variedades y en la investigación en el control } \\
\text { de plagas naturales. }\end{array}$} \\
\hline \multicolumn{5}{|c|}{$\begin{array}{l}\text { COMPRAS } \\
\text { Camposol cuenta con diversos proveedores de insumos de cajas de cartón, fertilizantes, pesticidas. }\end{array}$} \\
\hline $\begin{array}{l}\text { LOGÍSTICA DE ENTRADA } \\
\text { Stock de inventarios } \\
\text { de insumos necesarios } \\
\text { para la producción } \\
\text { y empaquetado } \\
\text { de sus productos. }\end{array}$ & $\begin{array}{l}\text { OPERACIONES } \\
\text { Laboratorios, } \\
\text { cosecha de } \\
\text { de cultivos, la } \\
\text { producción y } \\
\text { envasado de } \\
\text { sus productos. }\end{array}$ & \begin{tabular}{|l|} 
LOGÍSTICA DE SALIDA \\
Distribución \\
a los distintos \\
países a nivel \\
marítimo y aéreo
\end{tabular} & $\begin{array}{l}\text { MARKETING Y VENTAS } \\
\text { Cuenta con equipos } \\
\text { especializados } \\
\text { dedicados a la venta } \\
\text { en los distintos países, }\end{array}$ & $\begin{array}{l}\text { SERVICIOS } \\
\text { Ofrece una atención } \\
\text { al cliente rápida } \\
\text { a través de las } \\
\text { oficinas comerciales. }\end{array}$ \\
\hline
\end{tabular}

Fuente: Porter, M. (1985)

Elaboración propia 


\section{- Cadena de Valor UEN Mariscos}

Figura 1.3

\section{Cadena de valor UEN Mariscos}

\begin{tabular}{|c|c|c|c|c|}
\hline \multicolumn{5}{|l|}{$\begin{array}{l}\text { INFRAESTRUCTURA } \\
\text { Posee más de } 1,000 \\
\text { procesamiento. }\end{array}$} \\
\hline \multicolumn{5}{|c|}{$\begin{array}{l}\text { Camposol cuenta con un gran equipo especializado en toda la cadena de valor } \\
\text { que aporta el correcto funcionamiento en los distintos procesos internos, }\end{array}$} \\
\hline \multicolumn{5}{|c|}{$\begin{array}{l}\text { DESARROLLO DE TECNOLOGIA } \\
\text { Se convirtió más de } 50 \text { hectáreas a sistemas agrícolas intensivos que tienen un mayor rendimiento, } \\
\text { además posee dos nuevas plantas de procesamiento que cuenta con diversas certificaciones. }\end{array}$} \\
\hline \multicolumn{5}{|c|}{$\begin{array}{l}\text { COMPRAS } \\
\text { Compras de insumos requeridos para el correcto procesamiento del camarón y empaque } \\
\text { necesario para la distribución. }\end{array}$} \\
\hline $\begin{array}{l}\text { LOGÍSTICA DE ENTRADA } \\
\text { Stock de inventarios } \\
\text { de insumos necesarios } \\
\text { para la producción } \\
\text { y empaquetado } \\
\text { de sus productos. }\end{array}$ & $\begin{array}{l}\text { OPERACIONES } \\
\text { Laboratorios, } \\
\text { campos de } \\
\text { cultivos y } \\
\text { plantas de } \\
\text { procesamiento } \\
\text { de camarón. }\end{array}$ & $\begin{array}{l}\text { LOGÍSTICA DE SALIDA } \\
\text { Venta a } \\
\text { terceros que } \\
\text { realizan la venta } \\
\text { al cliente final, } \\
\text { hostelería y } \\
\text { servicios de } \\
\text { comidas. }\end{array}$ & $\begin{array}{l}\text { MARKETING Y VENTAS } \\
\text { Venta indirecta } \\
\text { a través de } \\
\text { intermediarios } \\
\text { hacia los clientes } \\
\text { finales. }\end{array}$ & $\begin{array}{l}\text { SERVICIOS } \\
\text { Ofrece } \\
\text { productos de } \\
\text { alta calidad con } \\
\text { trazabilidad } \\
\text { a través de } \\
\text { toda la cadena } \\
\text { de valor. }\end{array}$ \\
\hline
\end{tabular}

Fuente: Porter, M. (1985)

Elaboración propia

\section{- Cadena de Valor UEN Comercio}

Figura 1.4

Cadena de valor UEN Comercio

\begin{tabular}{|c|c|c|c|c|}
\hline \multicolumn{5}{|c|}{$\begin{array}{l}\text { INFRAESTRUCTURA } \\
\text { Oficinas comerciales ubicadas en Lima, Miami, Florida, Rotterdam y Shangai. }\end{array}$} \\
\hline \multicolumn{5}{|c|}{$\begin{array}{l}\text { RECURSOS HUMANOS } \\
\text { Cuenta con equipos multidisciplinarios enfocados en ventas, operaciones y administración. }\end{array}$} \\
\hline \multicolumn{5}{|c|}{$\begin{array}{l}\text { DESARROLLO DE TECNOLOGIA } \\
\text { Camposol se encuentra en constante investigación de los mercados a ingresar } \\
\text { Por ejemplo se detectó que en China se tiene preferencia por productos con características diferenciadas. }\end{array}$} \\
\hline \multicolumn{5}{|c|}{$\begin{array}{l}\text { COMPRAS } \\
\text { Creación de campañas para incentivar el consumo de aguacate en China, a través de publicidad que mostraba } \\
\text { los beneficios del aguacate en la salud y los usos en los platillos locales. }\end{array}$} \\
\hline $\begin{array}{l}\text { LOGÍSTICA DE ENTRADA } \\
\text { Recepción y transporte } \\
\text { de productos } \\
\text { provenientes del Perú. }\end{array}$ & $\begin{array}{l}\text { OPERACIONES } \\
\text { Acuerdos comerciales } \\
\text { con los distintos } \\
\text { minoristas en los } \\
\text { países destino como: } \\
\text { Walmart, Costco, } \\
\text { Kroger. }\end{array}$ & $\begin{array}{l}\text { LOGÍSTICA DE SALIDA } \\
\text { Distribución de } \\
\text { los pedidos a los } \\
\text { distintos minoristas } \\
\text { en los paises destino }\end{array}$ & $\begin{array}{l}\text { MARKETING Y VENTAS } \\
\text { Toma de pedidos, } \\
\text { análisis de venta } \\
\text { y búsqueda de nuevos } \\
\text { clientes mediante } \\
\text { investigación de } \\
\text { de mercados. }\end{array}$ & \begin{tabular}{|l|} 
SERVICIOS \\
Camposol ofrece \\
una comunicación \\
constante y cercana \\
con sus clientes para \\
resolver cualquier \\
incoveniente en el \\
menor tiempo posible.
\end{tabular} \\
\hline
\end{tabular}

Fuente: Porter, M. (1985)

Elaboración propia 


\subsubsection{Definición y sustentación de las ventajas competitivas de la empresa y por Unidad Estratégica de Negocio (UEN)}

Camposol posee tres UEN conformadas por UEN de Frutas y Verduras, la UEN de Mariscos y la UEN de Comercio.

"Cualquier cosa que una empresa haga especialmente bien en comparación con las empresas rivales. Cuando una empresa puede hacer algo que las empresas rivales no pueden, o tiene algo que sus rivales desean, eso representa una ventaja competitiva" (David, 2013, p. 8).

De acuerdo a lo expuesto por Fred David a continuación, se realiza la sustentación de las ventajas competitivas para cada UEN de Camposol:

\section{UEN Frutas y verduras:}

- Calidad Superior: Camposol en su unidad de negocio de Frutas y Verduras ofrece a sus clientes productos de una calidad superior, esto debido a que Camposol agrega materiales orgánicos a los campos de cultivos para proporcionar a las frutas y verduras de una mayor cantidad y calidad de nutrientes; por otro lado, en la producción agrícola Camposol utiliza riego por goteo impulsado por la gravedad minimizando el consumo de agua en sus campos de cultivo. Camposol se encuentra en constante investigación y en el desarrollo de nuevas tecnologías y procedimientos que ayuden a controlar las plagas naturales, la mayor parte de la producción de Camposol se comercializa fresca con lo cual Camposol gracias a su integración vertical asegura que su producción llegue en óptimas condiciones a los mercados extranjeros.

- Eficiencia Superior: Camposol optimiza el uso de sus recursos y de la eficiencia de sus procesos asegurando toda la cadena de valor desde el desarrollo de productos, sus procesos en campo, producción, envasado y distribución hacia sus clientes, a su vez Camposol se encuentra construyendo una nueva planta de empaque que calibrara la fruta por tamaño, mejorando la selección de sus cosechas para los distintos tipos de clientes y mercados internacionales, adicional a esto Camposol posee una estrategia de aprovechar la estacionalidad de los productos para cosechar sus cultivos y 
vender su producción ya que en épocas de alta demanda los precios tienden a aumentar, así mismo Camposol aprovecha la ventana de producción de los arándanos en el Perú que pueden ser producidos durante todo el año debido a las condiciones geográficas y climatológicas en el Perú en comparación de otros países que solo tienen una ventana de producción de 4 meses.

- Innovación Superior: Camposol se encuentra en constante innovación en el desarrollo de sus productos, posee una práctica de probar regularmente entre 15 a 20 nuevos cultivos y variedades de productos, esta práctica permitió a Camposol la producción de varios cultivos nuevos como los arándanos, por otro lado Camposol se encuentra redefiniendo sus procesos, mejorando la comunicación y el trabajo entre las áreas internas de la empresa para que los clientes puedan contar con los productos en el tiempo pactado, con el volumen requerido sin contratiempos para esto se simplifico el lado administrativo y se vinculó mejor las áreas que poseen.

- Mayor satisfacción al cliente: Camposol a través de sus oficinas comerciales en los distintos países aprovecha en ofrecer un mayor servicio a los minoristas en disponibilidad de productos, empaquetado, tiempo para culminar los pedidos y servicio al cliente, con lo cual Camposol posee una comunicación constante y cercana con sus clientes a fin de resolver cualquier inconveniente en el menor tiempo posible.

\section{UEN Mariscos}

- Calidad Superior: Camposol en su unidad de negocio de mariscos ofrece productos de alta calidad principalmente a los mercados de EEUU y China, los mariscos que produce Camposol poseen una alta calidad en proteínas, a su vez que son productos eco amigables y socialmente responsable con las comunidades aledañas, por otro lado, Camposol asegura su producción a través de sus laboratorios, campos de cultivos y plantas de procesamiento que los mariscos lleguen en óptimas condiciones con las condiciones de frio para el transporte hacia los clientes finales.

- Eficiencia Superior: Camposol convirtió 50 hectáreas a sistemas agrícolas intensivos obteniendo así un aumento considerable en los rendimientos por cosecha alcanzando $30 \mathrm{TM}$ por hectárea de cosecha (tres veces por año), 
siendo estos rendimientos mucho más altos que los estanques convencionales, por otro lado, Camposol adquirió dos plantas de procesamiento de camarón a finales del 2014 que cuentan con una alta tecnología para congelar diferentes tipos de langostino y asegurar la calidad de sus productos.

- Innovación Superior: Camposol se encuentra innovando en sus procesos y sistemas para poder obtener una mayor cantidad de rendimiento por hectárea de cosecha de camarón a su vez posee una integración vertical desde los campos de cultivos, laboratorios de larvas y plantas de procesamiento lo cual le permite poder tener una trazabilidad de toda su producción asegurando su cadena de valor.

- Mayor satisfacción al cliente: Camposol posee distintas certificaciones internacionales que aseguran la calidad, inocuidad de sus productos otorgando así a sus productos de alta calidad y que estos lleguen en óptimas condiciones a sus clientes finales en los mercados extranjeros que son los clientes de hostelería y servicio de comidas.

\section{UEN Comercio}

- Calidad Superior: Camposol a través de sus oficinas comerciales en los distintos países asegura que los pedidos de sus clientes cumplan sus requerimientos en las condiciones acordadas de empaque, cantidad, calidad y precio.

- Eficiencia Superior: Camposol posee una integración vertical asegurando toda la cadena de valor desde el laboratorio, cultivos, producción, envasado y distribución hasta los mercados destinos, con lo cual Camposol en los mercados destino puede vender directamente sus productos a los grandes minoristas.

- Innovación Superior: Camposol se encuentra en constante investigación de mercado en los nuevos mercados internacionales donde opera para poder conocer las preferencias de los consumidores con el fin de adaptar sus productos a la demanda y necesidades del consumidor, un claro ejemplo de esto es que Camposol detecto la preferencia estética por parte del mercado chino donde el tamaño, color y apariencia son factores importantes de 
decisión por parte del consumidor. Por otro lado, en China Camposol se encuentra realizando campañas que muestran los beneficios del consumo del aguacate y la preparación e incorporación en la comida.

- Mayor satisfacción al cliente: Camposol a través de sus oficinas comerciales posee una comunicación constante y cercana con los clientes con el fin de resolver cualquier duda o problema que surja y sea resuelta en el menor tiempo posible.

\subsubsection{Determinación y sustentación de las Fortalezas y Debilidades de la empresa y por Unidad Estratégica de Negocio (UEN)}

\section{UEN Frutas y Verduras}

\section{Fortalezas}

- Calidad Superior en los productos: Camposol ofrece frutas y verduras con características diferenciadas a los clientes en los mercados extranjeros, a través de sus productos de alto valor nutritivo, asegurando la cantidad y calidad de nutrientes en sus productos a través de materiales orgánicos en los sembríos, además Camposol asegura toda la cadena de valor para que los productos puedan llegar en tiempo y calidad requerida a los clientes extranjeros.

- Producción de productos orgánicos: Camposol posee una pequeña cantidad de producción orgánica lo cual le permite ingresar y negociar con los minoristas asegurando también la venta de sus productos convencionales, los supermercados se encuentran interesados en tener acceso a la producción orgánica de Camposol, por otro lado, la producción de productos orgánicos posee un mayor margen potencial en el futuro, con lo cual se convierte en parte clave de su portafolio de productos.

- Prueba de Nuevos cultivos: Camposol posee la práctica de probar constantemente entre 15 a 20 nuevos cultivos y variedades, eso ha generado la producción de nuevos cultivos entre ellos los arándanos, cultivo principal actual de Camposol. 
- Zona geográfica privilegiada: Camposol se encuentra localizada en la costa norte del Perú, donde las condiciones geográficas generan un ecosistema muy importante y privilegiado, como resultado Camposol puede producir frutas que se encuentran en los hemisferios norte y sur durante muchos meses apuntando a las ventanas del mercado internacional cuando la demanda y los precios de los productos son más altos, generando una mayor rentabilidad.

- Integración Vertical: Camposol posee una estrategia de integración vertical, posee toda la cadena de valor desde el desarrollo de productos, los cultivos, la recolección, empaquetado y transporte hasta los mercados de destino en donde se realiza la venta directa a través de sus oficinas comerciales asegurando así la distribución a las grandes cadenas minoristas.

- Acuerdos comerciales: Camposol posee acuerdos comerciales con distintos minoristas asegurando un gran volumen a los minoristas y aprovechando su modelo integrado y su integración vertical le permite ofrecer grandes volúmenes de productos a los precios acordados con los clientes.

- Portafolio de productos: Camposol posee un portafolio variado de productos entre ellos se encuentran: La palta, los espárragos, la palta, uvas, mangos, arándanos, entre otros siendo el arándano el producto que ha presentado un crecimiento acelerado y gracias a los arándanos y a la preferencia de este producto por parte de los minoristas, Camposol puede entablar relaciones con cualquier minorista y presentar el resto de su portafolio de productos.

\section{Debilidades}

- Crecimiento rápido: Camposol experimentó un crecimiento rápido en los últimos años con lo cual no fue de manera orgánica y ordenada debido a eso se generaban inconvenientes en los procesos y controles internos generando fricción entre las diversas áreas de la compañía y dificultando la entrega de los pedidos a sus clientes.

- Poca Diferenciación en las frutas: La diferenciación en la fruta no está tan evolucionada a nivel mundial con lo cual Camposol está en búsqueda de añadir una diferenciación en sus productos enfocada en sus atributos como 
empresa ya que es una empresa social y ambientalmente responsable, lo cual puede significar un impacto positivo para el cliente final.

- Estrategia de Marca no desarrollada: Camposol no tiene definida una estrategia de marca con lo que el cliente final en este caso el consumidor aún no reconoce a Camposol como una marca de calidad que ofrece productos de alto valor nutritivo y es socialmente responsable.

- Mano de Obra escaza: Camposol gasta más de 1 millón de dólares en transportar a los trabajadores de sus lugares de origen a los campos con lo cual no contaba con una fuerza de trabajo sostenible localmente.

- Dependencia a la Producción peruana: La dependencia de Camposol a la producción peruana lo somete a las dificultades que pueda enfrentar el Perú como riesgos políticos, efectos climáticos como el fenómeno del niño y depender de los proyectos de agua a nivel nacional para el cultivo de nuevas áreas geográficas.

- Concentración de Productos: Camposol concentra la mayor parte de sus ventas en pocos productos, lo cual lo hace muy susceptible a los cambios que se puedan suscitar en dichas categorías de productos.

\section{UEN Mariscos}

\section{Fortalezas}

- Sistemas agrícolas intensivas: Camposol posee más de 1,000 hectáreas de campos de cultivos, a través de una nueva tecnología Camposol se encuentra maximizando los rendimientos por hectárea de camarón. Asegurando una producción mayor durante todo el año.

- Certificaciones internacionales: Camposol posee diversas certificaciones internacionales como: HACCP, BRC, BASC y BAP, lo cual asegura altos estándares de seguridad, calidad e inocuidad en sus productos.

- Integración Vertical: Camposol posee una integración vertical en su línea de mariscos, posee un laboratorio donde produce y cultiva las larvas que posteriormente se siembran en sus campos de cultivos y cuenta con varias plantas de procesamiento con una alta tecnología para la congelación de sus 
productos, toda esta cadena de valor le permite tener una trazabilidad de toda su producción.

\section{Debilidades}

- Volumen de producción: Camposol no posee volúmenes de producción suficientemente grandes para suministrar en el momento oportuno a los minoristas, con lo cual aún no vende su producción directamente a los clientes finales.

- Dependencia de la producción peruana: La producción de mariscos de Camposol está concentrada en el norte del Perú, con lo cual Camposol se encuentra expuesto a los cambios climáticos o fenómenos que sucedan en esos lugares, en el año 2015 la mortalidad del camarón aumento debido al fenómeno del niño afectando negativamente a Camposol.

- Venta por intermediarios: Camposol en su unidad de negocio de mariscos no vende directamente sus productos a los clientes debido a que no puede asegurar los volúmenes de productos requeridos por los minoristas, con lo cual pierde el valor de marca hacia el consumidor final.

\section{UEN Comercio}

\section{Fortalezas}

- Ubicación estratégica: Camposol cuenta con cuatro oficinas comerciales a nivel mundial estas se encuentran ubicadas en: Lima, Florida, Rotterdam y Shanghái, desde estas oficinas establece relaciones comerciales a largo plazo con sus clientes internacionales.

- Investigación de mercados: A través de las oficinas comerciales en los mercados destinos Camposol puede conocer los gustos y características de los clientes en dichas regiones y adaptar su oferta para cumplir con los requerimientos de los clientes.

- Cercanía para resolver problemas: Facilita la comunicación con los clientes en los mercados destinos y facilita la entrega de productos en 
cantidad, calidad, empaquetado y resolución de problemas en el menor tiempo posible, ofreciendo una alta calidad de servicio a sus clientes.

- Acuerdos comerciales: A través de las oficinas comerciales Camposol está en búsqueda de nuevos clientes para realizar acuerdos para la comercialización de su portafolio de productos.

\section{Debilidades}

- Dependencia de la producción peruana: Las oficinas comerciales están sujetas a la producción y calidad de la producción peruana con lo cual las oficinas comerciales tienen ciertas limitantes para las negociaciones con los minoristas extranjeros.

- Mercado Fragmentado China: El mercado en China se encuentra fragmentado con lo cual para Camposol se le presenta una dificultad para poder llegar a gran parte de los clientes finales por la cantidad de negociaciones y acuerdos con los distintos minoristas a lo largo de todo el país.

- Centros de maduración: Camposol posee una dependencia de los centros de maduración de terceros o de clientes para la maduración de sus productos en los mercados destinos, siendo esta una desventaja principalmente en la venta a pequeños minoristas con lo cual Camposol otorga su producción a terceros donde ellos se encargan de la maduración y posterior venta a los minoristas.

\subsection{Diagnóstico Externo}

\subsubsection{Análisis PEST (Sustentación de las fuerzas en base a la evolución futura de factores)}

David (2013) señala: "Identificar y evaluar las oportunidades y amenazas externas permite que las organizaciones desarrollen una misión clara, diseñen estrategias para lograr sus objetivos a largo plazo y generen políticas para alcanzar sus objetivos anuales" (p. 64).

Se analizará las variables que tienen alguna incidencia en Camposol y su evolución en el corto, mediano y largo plazo, se determinará si estos factores representan una oportunidad o una amenaza para Camposol tanto en el presente como en su evolución si el impacto se mantiene de manera positiva o negativa. 
Tabla 1.1

\section{Análisis PEST}

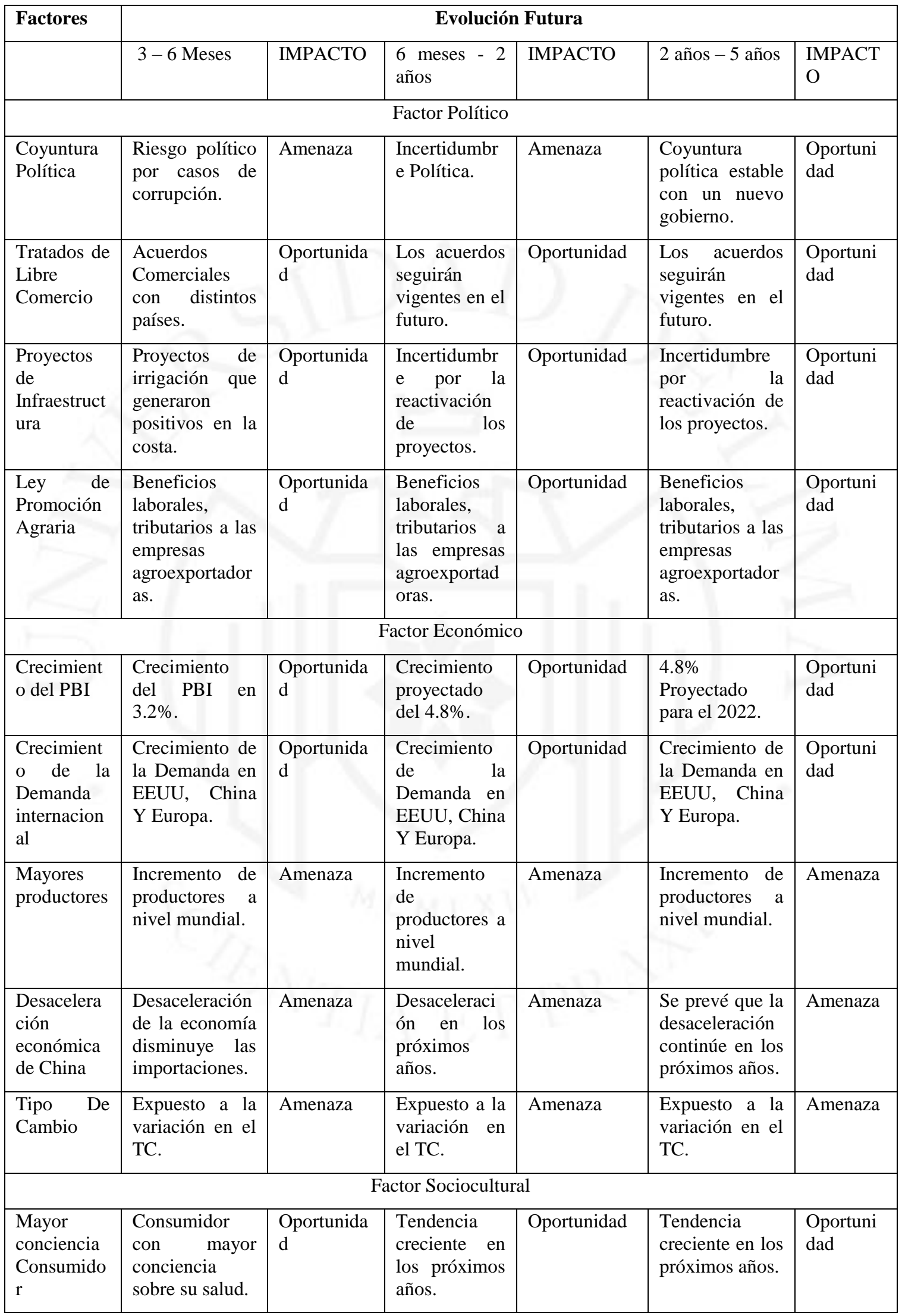




\section{(continuación)}

\begin{tabular}{|c|c|c|c|c|c|c|}
\hline $\begin{array}{l}\text { Auditorias } \\
\text { Sociales, } \\
\text { ambientales } \\
\text { y sanitarias }\end{array}$ & $\begin{array}{l}\text { Estándares } \\
\text { necesarios } \\
\text { para los } \\
\text { mercados } \\
\text { internacional } \\
\text { es. }\end{array}$ & Oportunidad & $\begin{array}{l}\text { Estos } \\
\text { estándares se } \\
\text { seguirán } \\
\text { requiriendo } \\
\text { cada vez más } \\
\text { para las } \\
\text { exportaciones }\end{array}$ & Oportunidad & $\begin{array}{l}\text { Estos } \\
\text { estándares se } \\
\text { seguirán } \\
\text { requiriendo } \\
\text { cada vez más } \\
\text { para las } \\
\text { exportaciones. }\end{array}$ & $\begin{array}{l}\text { Oportuni } \\
\text { dad }\end{array}$ \\
\hline $\begin{array}{l}\text { Mano de } \\
\text { Obra escasa } \\
\text { en la Zona. }\end{array}$ & $\begin{array}{l}\text { Costos altos } \\
\text { en movilidad } \\
\text { de } \\
\text { trabajadores. }\end{array}$ & Amenaza & $\begin{array}{l}\text { Costos altos } \\
\text { en movilidad } \\
\text { de } \\
\text { trabajadores. }\end{array}$ & Amenaza & $\begin{array}{l}\text { Financiación de } \\
\text { proyectos de } \\
\text { vivienda para } \\
\text { empleados. }\end{array}$ & $\begin{array}{l}\text { Oportuni } \\
\text { dad }\end{array}$ \\
\hline $\begin{array}{l}\text { Mano de } \\
\text { obra Barata }\end{array}$ & $\begin{array}{l}\text { Mano de obra } \\
\text { barata a } \\
\text { comparación } \\
\text { de EEUU y } \\
\text { Europa. }\end{array}$ & Oportunidad & $\begin{array}{l}\text { Mano de obra } \\
\text { barata a } \\
\text { comparación } \\
\text { de EEUU y } \\
\text { Europa. }\end{array}$ & Oportunidad & $\begin{array}{lr}\text { Mano de } & \text { obra } \\
\text { barata } & \text { a } \\
\text { comparación de } \\
\text { EEUU } \\
\text { Europa. }\end{array}$ & $\begin{array}{l}\text { Oportuni } \\
\text { dad }\end{array}$ \\
\hline \multicolumn{7}{|c|}{ Factor Tecnológico } \\
\hline $\mathrm{I}+\mathrm{D}$ & $\begin{array}{l}\text { Nuevos } \\
\text { cultivos y } \\
\text { variedades e } \\
\text { investigación } \\
\text { de control de } \\
\text { plagas. }\end{array}$ & Oportunidad & $\begin{array}{l}\text { Desarrollo de } \\
\text { nuevos } \\
\text { cultivos y } \\
\text { variedades de } \\
\text { productos. }\end{array}$ & Oportunidad & $\begin{array}{l}\text { Desarrollo de } \\
\text { nuevos cultivos } \\
\text { y variedades de } \\
\text { productos. }\end{array}$ & $\begin{array}{l}\text { Oportuni } \\
\text { dad }\end{array}$ \\
\hline $\begin{array}{l}\text { Nuevas } \\
\text { Tecnología } \\
\text { s }\end{array}$ & $\begin{array}{l}\text { Automatizaci } \\
\text { ón de } \\
\text { procesos y } \\
\text { calibración de } \\
\text { la fruta. }\end{array}$ & Oportunidad & $\begin{array}{l}\text { Automatizaci } \\
\text { ón de } \\
\text { procesos y } \\
\text { calibración de } \\
\text { la fruta. }\end{array}$ & Oportunidad & $\begin{array}{l}\text { Automatizació } \\
\mathrm{n} \text { de procesos y } \\
\text { calibración de } \\
\text { la fruta. }\end{array}$ & $\begin{array}{l}\text { Oportuni } \\
\text { dad }\end{array}$ \\
\hline $\begin{array}{l}\text { Comercio } \\
\text { Electrónico }\end{array}$ & $\begin{array}{l}\text { Preferencia } \\
\text { de canales } \\
\text { electrónicos. }\end{array}$ & Oportunidad & $\begin{array}{l}\text { Preferencia } \\
\text { de canales } \\
\text { electrónicos. }\end{array}$ & Oportunidad & $\begin{array}{l}\text { Preferencia de } \\
\text { canales } \\
\text { electrónicos }\end{array}$ & $\begin{array}{l}\text { Oportuni } \\
\text { dad }\end{array}$ \\
\hline \multicolumn{7}{|c|}{ Factor Ecológicos } \\
\hline $\begin{array}{l}\text { Cambio } \\
\text { Climático }\end{array}$ & $\begin{array}{l}\text { Amenazan la } \\
\text { producción } \\
\text { de alimentos. }\end{array}$ & Amenaza & $\begin{array}{l}\text { Amenazan la } \\
\text { producción } \\
\text { de alimentos. }\end{array}$ & Amenaza & $\begin{array}{ll}\text { Amenazan } & \text { la } \\
\text { producción } & \text { de } \\
\text { alimentos. } & \end{array}$ & Amenaza \\
\hline $\begin{array}{l}\text { Fenómeno } \\
\text { del Niño }\end{array}$ & $\begin{array}{l}\text { Consecuencia } \\
\mathrm{s} \text { negativas } \\
\text { para la } \\
\text { producción } \\
\text { peruana. }\end{array}$ & Amenaza & $\begin{array}{l}\text { Los efectos se } \\
\text { irán } \\
\text { incremento } \\
\text { en el futuro. }\end{array}$ & Amenaza & $\begin{array}{l}\text { Los efectos se } \\
\text { irán incremento } \\
\text { en el futuro. }\end{array}$ & Amenaza \\
\hline $\begin{array}{l}\text { Conciencia } \\
\text { Social } \\
\text { ecológica }\end{array}$ & $\begin{array}{l}\text { Mayor } \\
\text { conciencia } \\
\text { valorando } \\
\text { productos } \\
\text { responsables } \\
\text { con el medio } \\
\text { ambiente. }\end{array}$ & Oportunidad & $\begin{array}{l}\text { Mayor } \\
\text { conciencia } \\
\text { valorando } \\
\text { productos } \\
\text { responsables } \\
\text { con el medio } \\
\text { ambiente. }\end{array}$ & Oportunidad & $\begin{array}{l}\text { Mayor } \\
\text { conciencia } \\
\text { valorando } \\
\text { productos } \\
\text { responsables } \\
\text { con el medio } \\
\text { ambiente. }\end{array}$ & $\begin{array}{l}\text { Oportuni } \\
\text { dad }\end{array}$ \\
\hline
\end{tabular}

Ministerio de Economía y Finanzas (2019); El Comercio (2018); Diario El Peruano (2019); Ley N. 27360 (2002); MEF (2019); Naciones Unidas (2019)

Elaboración propia 


\subsubsection{Análisis de las fuerzas competitivas del sector}

Hitt, Ireland y Hoskisson (2015) señalan: "Para estudiar una industria, la compañía analiza cinco fuerzas que afectan la capacidad de todas las compañías para operar de forma rentable dentro de esa industria" (p. 52).

Según Chiavenato y Sapiro (2011) El análisis de las cinco fuerzas amplía la base analítica del sector, en razón de que se muestra que la competencia envuelve a todas las organizaciones que pertenecen a un mismo sector (p. 101).

\section{Rivalidad entre empresas competidoras}

Para analizar la rivalidad se tendrá en cuenta la participación de las exportaciones por categorías de producto, en este caso se analizará los principales productos de Camposol los cuales son: Los arándanos, espárragos y aguacates. Se tomará de base la información de SIICEX.

\section{Arándanos}

En el mercado de Arándanos Camposol cuenta con una participación del 32\% de las exportaciones en el Perú en el año 2018, con lo cual es el principal exportador de arándanos del Perú.

Figura 1.5

Participación de empresas exportadoras de arándanos

\begin{tabular}{|l|l|l|}
\hline \multicolumn{1}{|c|}{ Empresa } & $\%$ Var & $\%$ Part. \\
\hline CAMPOSOL S.A. & $18-17$ & 18 \\
\hline HORTIFRUT-TAL S.A.C. & $50 \%$ & $32 \%$ \\
\hline HFE BERRIES PERU S.A.C. & - & $13 \%$ \\
\hline AGRICOLA SANTA AZUL S.A.C & $25 \%$ & $11 \%$ \\
\hline HASS PERU S.A. & $180 \%$ & $6 \%$ \\
\hline AGRICOLA CERRO PRIETO S.A. & $25 \%$ & $6 \%$ \\
\hline AGROBERRIES PERU S.A.C. & $11 \%$ & $4 \%$ \\
\hline TAL S A & $180 \%$ & $4 \%$ \\
\hline Otras Empresas (56) & $288 \%$ & $4 \%$ \\
\hline
\end{tabular}

Fuente: SIICEX (2019a) 


\section{Espárragos}

Camposol no figura entre los principales exportadores de espárragos en el Perú, contando así con una participación inferior al $4 \%$ en esta categoría de producto.

Figura 1.6

Participación de empresas exportadoras de espárragos

PRINCIPALES EMPRESAS EXPORTADORAS

\begin{tabular}{|l|l|l|}
\hline \multicolumn{1}{|c|}{ Empresa } & $\%$ Var & $\%$ Part. \\
\hline COMPLEJO AGROINDUSTRIAL BETA S.A. & $-7 \%$ & $13 \%$ \\
\hline DANPER TRUJILLO S.A.C. & $6 \%$ & $12 \%$ \\
\hline SOCIEDAD AGRICOLA DROKASA S.A. & $-8 \%$ & $5 \%$ \\
\hline EMPRESA AGRO EXPORT ICA S.A.C. & $-24 \%$ & $4 \%$ \\
\hline SANTA SOFIA DEL SUR S.A.C. & $-28 \%$ & $4 \%$ \\
\hline FLORIDABLANCA S.A.C. & $-13 \%$ & $4 \%$ \\
\hline AGRO PARACAS S.A. & $14 \%$ & $4 \%$ \\
\hline CE COMERCIAL S.A.C. & $217 \%$ & $4 \%$ \\
\hline AGRICOLA LA VENTA S.A. & $-9 \%$ & $4 \%$ \\
\hline Otras Empresas (83) & - & $40 \%$ \\
\hline Fuente: SIICEX (2019b) & & \\
\hline
\end{tabular}

\section{Aguacates}

Camposol es líder en las exportaciones de aguacates a nivel nacional contando con una participación de $14 \%$ en el año 2018.

\section{Figura 1.7}

Participación de empresas exportadoras de aguacates

PRINCIPALES EMPRESAS EXPORTADORAS

\begin{tabular}{|l|l|l|}
\hline \multicolumn{1}{|c|}{ Empresa } & \multicolumn{1}{c|}{$\% \mathrm{Var}$} & $\%$ Part. \\
\hline CAMPOSOL S.A. & $20 \%$ & $14 \%$ \\
\hline SOCIEDAD AGRICOLA DROKASA S.A. & $8 \%$ & $9 \%$ \\
\hline AVOCADO PACKING COMPANY S.A.C. & $-30 \%$ & $8 \%$ \\
\hline AGRICOLA CERRO PRIETO S.A. & $67 \%$ & $6 \%$ \\
\hline CAMET TRADING S.A.C. & $58 \%$ & $5 \%$ \\
\hline VIRU S.A. & $2 \%$ & $4 \%$ \\
\hline CONSORCIO DE PRODUCTORES DE FRUTA... & $-17 \%$ & $3 \%$ \\
\hline ASR TRADING SOCIEDAD ANONIMA CERRADA & $46 \%$ & $3 \%$ \\
\hline AGROINDUSTRIAS VERDEFLOR S.A.C. & $104 \%$ & $2 \%$ \\
\hline OtraS EmPresas (180) & - & $35 \%$ \\
\hline Fuente: SIICEX (2019C) & & \\
\hline
\end{tabular}


Con la información obtenida se analizará la rivalidad de empresas competidoras mediante unas variables:

- Estructura de la industria: La estructura de la industria es fragmentada ya que distintas empresas de distintos países compiten directamente con Camposol, si bien Camposol es una de las empresas con mayor nivel de exportación a nivel nacional a nivel internacional posee una competencia aún mayor.

- Crecimiento de la demanda: La demanda en el mercado internacional con respecto a los arándanos se encuentra en pleno crecimiento como se detalla en el siguiente gráfico la producción mundial de arándanos paso de 339 TM en el 2009 a 596 TM en el 2017 significando un crecimiento del 75\% en un lapso de 8 años, con la incursión en nuevos mercados como Asia en los próximos años la producción seguirá en aumento, y al no ser un mercado saturado genera que la rivalidad disminuya.

Figura 1.8

Producción mundial de arándanos

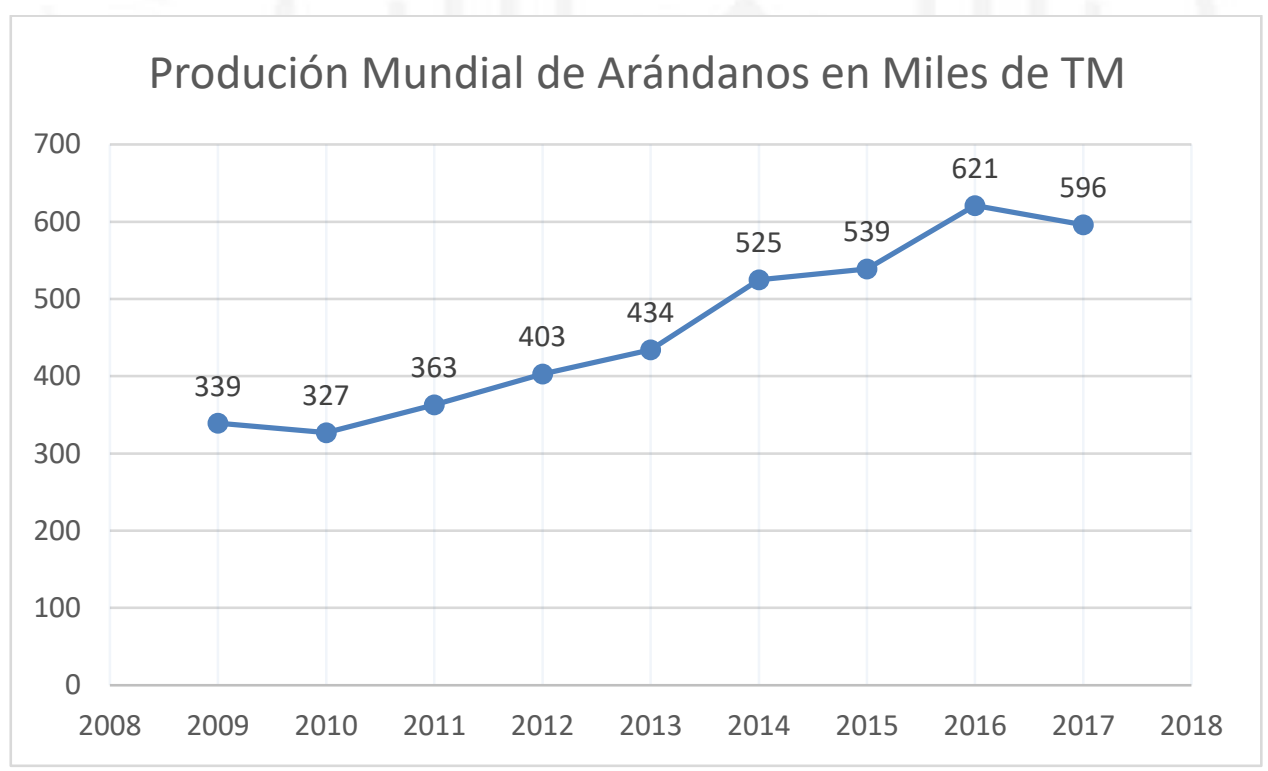

Fuente: Banco Mundial (2019)

Elaboración Propia

- Diferenciación del producto: La diferenciación del producto es baja ya que el cliente final no llega a percibir las diferencias entre los productos de Camposol y el de las empresas competidoras, con lo cual la rivalidad aumenta. 
- Barreras de Salida: Las barreras de salida en el sector son altas, ya que las compañías poseen altos costos fijos como la mano de obra, las instalaciones, planta, áreas de cultivo además que los productos son perecederos, con lo que la rivalidad aumenta.

- Costo de Cambio: Al ser productos con una muy poca diferenciación los consumidores pueden cambiar de marca fácilmente lo que genera que la rivalidad aumente.

De acuerdo a los aspectos analizados se concluye que la rivalidad de las empresas competidoras en el sector es Alta.

Poder de Negociación de los compradores: El poder de negociación de los compradores es baja, Camposol posee un portafolio diferenciado de productos convencionales y orgánicos que le permite negociar con los minoristas y a su vez Camposol aprovecha las ventanas de demanda alta para ofrecer sus productos a los distintos minoristas.

Amenaza de ingreso de competidores potenciales: La amenaza de ingreso de competidores es alta debido a que es un mercado rentable y que se encuentra en pleno crecimiento, con lo cual genera interés de nuevos competidores para el acceso a este mercado, sin embargo, el mercado exige ciertas normativas en términos de certificaciones de calidad, inocuidad lo cual representa una limitación para las nuevas empresas que quieran entrar al sector.

Poder de negociación de los proveedores: El poder de negociación de los proveedores es baja ya que Camposol negocia grandes volúmenes de compra, obteniendo así mejores tratos comerciales con sus respectivos proveedores, entre sus proveedores se encuentran: Fertilizantes, productos agroquímicos, cajas de cartón, semillas, maquinaria.

Amenaza de productos sustitutos: La amenaza de productos sustitutos es alta ya que el consumidor puede optar por cualquier otra variedad de frutas y verduras que cumplan los mismos requerimientos que los productos ofrecidos por Camposol que se encuentren disponibles en los puntos de venta al cliente final.

\subsubsection{Determinación y sustentación de Oportunidades y Amenazas}

\section{Oportunidades:}


- Tratados de Libre Comercio con otros países: Los TLC son acuerdos que de dos o más países para acordar la reducción de barreras no arancelarias y acordar la concesión de preferencias arancelarias mutuas, en la actualidad Perú posee acuerdos regionales: Comunidad Andina, Mercosur, Acuerdos multilaterales: OMC, APEC y acuerdos de comercio bilaterales, estos tratados favorecen la apertura de nuevos mercados y la reducción de aranceles y barreras y facilita a las empresas peruanas la venta de sus productos a mercados extranjeros.

- Construcción de Proyectos de Irrigación: Los proyectos de irrigación impulsados por el Estado peruano dotaron de agua a las costas peruanas lo cual favoreció la producción agrícola, en la actualidad existen algunos proyectos pendientes: Alto Piura, Olmos, Chavimochic 3, entre otros.

- Crecimiento del PBI: El Perú presenta un crecimiento prolongado en los últimos 18 años por el aumento de las materias primas que impulso el crecimiento y redujo la tasa de pobreza, sin embargo, en los últimos años el crecimiento se ha estancado debido a una menor demanda de los productos básicos del Perú.

Figura 1.9

Crecimiento del PBI

\section{Crecimiento del PBI}

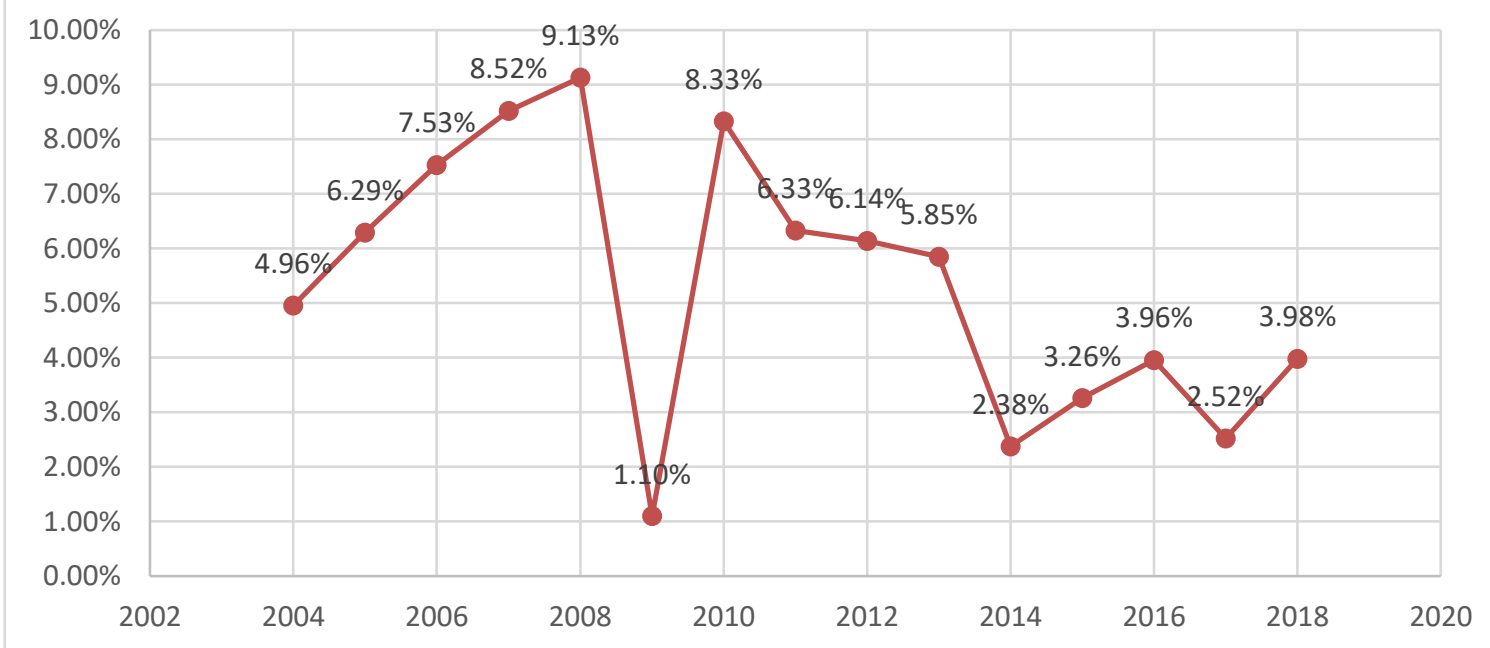

Fuente: Banco Mundial (2019)

Elaboración propia 
- Mayor Conciencia del Consumidor: El consumidor actual posee una mayor conciencia respecto a su salud y a los productos que consume por eso prefiere el consumo de productos de alto valor nutritivo que aporten características únicas y que las empresas sean responsables socialmente y ambientalmente lo cual marca un diferencial al momento de la compra del producto.

- Auditorias Sociales, ambientales y sanitarias: Los mercados extranjeros poseen ciertos estándares de exigencia para las empresas exportadoras, dentro de estas exigencias se encuentran que las empresas deben contar con auditorias sociales, ambientales y sanitarias con el fin de garantizar que las compañías tengan un impacto positivo en el ambiente que operan y ofrezcan un producto de alta calidad.

- Tecnología: Los avances en la tecnología permiten el estudio de nuevas variedades de cultivos y la mitigación de plagas naturales, a su vez que moderniza los procesos a través de la automatización de ciertos procesos industriales.

- Preferencia productos orgánicos: Existe una tendencia creciente por parte del consumidor, las preferencias por estos productos orgánicos están enfocados por motivos de salud y una percepción de una calidad superior del producto.

\section{Amenazas:}

- Inestabilidad Política que atraviesa el Perú en los últimos años: En los últimos años el Perú se está enfrentando a una crisis política, debido a los casos de corrupción que se han presentado por parte Odebrecht y otras empresas constructoras y varios presidentes presentan serios cuestionamientos, razón por la cual varios proyectos de construcción en el Perú han quedado paralizados como: Olmos, Chavimochic III.

- Escasez de Mano de Obra en la zona: La zona en donde opera sus actividades Camposol no posee población con lo cual contrato personal de otros lugares y gasta en transporte hacia los campos de cultivo de Camposol.

- Cambios Climáticos: El cambio climático es uno de los mayores desafíos de la actualidad, los gases de efecto invernado se han incrementado los efectos de esto es un aumento en la temperatura media de la tierra que 
ocasiona un aumento en el nivel del mar, riesgo de inundaciones y amenazan la producción de alimentos.

- Fenómeno del Niño: El fenómeno del niño ocasiona un aumento en la temperatura de las aguas de la costa que ocasiona el aumento de lluvias intensas, perdidas pesqueras, huaycos que afectan a la población y a los cultivos.

- Generación de nuevos competidores a nivel nacional e internacional: Debido al crecimiento de los mercados internacionales y a una mayor demanda, existe un interés de parte de otras compañías nacionales e internacionales para ingresar al sector. 


\section{CAPÍTULO II: FORMULACIÓN DE LA ESTRATEGIA}

\subsection{Desarrollo y sustentación de la Matriz EFI}

Para el desarrollo de la Matriz EFI (Evaluación de los factores internos) se toma en cuenta las fortalezas y debilidades de la compañía descritas en el punto 1.1.

La Matriz de evaluación de factores internos (EFI) es una síntesis dentro del proceso de auditoría interna de la administración estratégica. Esta herramienta para la formulación de estrategias sintetiza y evalúa las fortalezas y debilidades más importantes encontradas en las áreas funcionales de una empresa y también constituye la base para identificar y evaluar las relaciones entre estas áreas.

(David, 2013, p. 122).

Tabla 2.1

Matriz EFI

\begin{tabular}{|c|c|c|c|}
\hline+2 & VALOR & CALIFICACIÓN & V. PONDERADO \\
\hline \multicolumn{4}{|l|}{ FORTALEZAS } \\
\hline Calidad Superior en los productos(F1) & 0.10 & 4 & 0.40 \\
\hline Producción de productos orgánicos(F2) & 0.02 & 3 & 0.06 \\
\hline Prueba de nuevos cultivos(F3) & 0.03 & 3 & 0.09 \\
\hline Integración Vertical(F4) & 0.10 & 4 & 0.40 \\
\hline Zona geográfica privilegiada(F5) & 0.08 & 4 & 0.32 \\
\hline Acuerdos Comerciales(F6) & 0.10 & 4 & 0.40 \\
\hline Certificaciones Internacionales(F7) & 0.10 & 4 & 0.40 \\
\hline \multicolumn{4}{|l|}{ DEBILIDADES } \\
\hline Crecimiento desordenado(D1) & 0.10 & 2 & 0.20 \\
\hline Estrategia de Marca no implementada(D2) & 0.05 & 2 & 0.10 \\
\hline Mano de Obra Escasa en la zona(D3) & 0.07 & 1 & 0.07 \\
\hline Concentración de Productos(D4) & 0.15 & 1 & 0.15 \\
\hline Dependencia de la Producción peruana(D5) & 0.10 & 2 & 0.20 \\
\hline TOTAL & $\mathbf{1}$ & & 2.79 \\
\hline
\end{tabular}

Fuente: Bell, D.E., y Kindred, N.(2016), David (2013)

Elaboración Propia

El valor ponderado que se ha obtenido para Camposol es de 2.79 eso significa que la empresa es internamente fuerte, capitalizando sus fortalezas y neutralizando sus debilidades, gracias al enfoque en la calidad y la cadena de valor que ofrecen en todos sus productos. 


\subsection{Desarrollo y sustentación de la matriz EFE}

David (2013) señala: "La Matriz de evaluación de factores externos (EFE) permite que los estrategas resuman y evalúen información económica, social, cultural, demográfica, ambiental, política, gubernamental, legal, tecnológica y competitiva" (p. 80).

Tabla 2.2

Matriz EFE

\begin{tabular}{|c|c|c|c|}
\hline 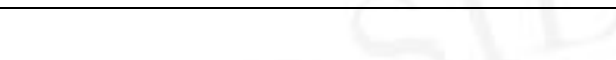 & VALOR & CALIFICACIÓN & V. PONDERADO \\
\hline \multicolumn{4}{|l|}{ OPORTUNIDADES } \\
\hline TLC(O1) & 0.10 & 4 & 0.40 \\
\hline Proyectos de infraestructura $(\mathrm{O} 2)$ & 0.10 & 4 & 0.40 \\
\hline Crecimiento PBI en $3.4 \%$ (O3) & 0.05 & 3 & 0.15 \\
\hline Ley de promoción agraria $(\mathrm{O} 4)$ & 0.10 & 4 & 0.40 \\
\hline Auditorias Sociales y ambientales(O5) & 0.05 & 3 & 0.15 \\
\hline Conciencia del consumidor(O6) & 0.05 & 4 & 0.20 \\
\hline Medios electrónicos de comunicación(O7) & 0.05 & 4 & 0.20 \\
\hline \multicolumn{4}{|l|}{ AMENAZAS } \\
\hline Inestabilidad Política en el Perú(A1) & 0.10 & 2 & 0.20 \\
\hline Desaceleración de la economía China(A2) & 0.05 & 2 & 0.10 \\
\hline Escasez mano de Obra(A3) & 0.10 & 2 & 0.20 \\
\hline Cambios climáticos(A4) & 0.06 & 1 & 0.06 \\
\hline Nuevos Competidores(A5) & 0.05 & 1 & 0.05 \\
\hline Tipo de cambio(A6) & 0.04 & 2 & 0.08 \\
\hline Fenómeno del niño(A7) & 0.10 & 1 & 0.10 \\
\hline Total & $\mathbf{1}$ & & 2.69 \\
\hline
\end{tabular}

Fuente: Bell, D.E., y Kindred, N.(2016), David (2013)

Elaboración Propia

El valor ponderado Obtenido por Camposol en la Matriz EFE arroja un puntaje de 2.69 con lo cual Camposol está aprovechando las oportunidades y minimiza las amenazas externas, sin embargo, se presentan áreas de mejora. 


\subsection{Matriz de la Estrategias Genéricas (Sustento)}

Según Peteraf y Strickland (2012) La estrategia competitiva de una empresa comprende las especificaciones del plan de la administración para competir con éxito y el tipo de ventaja competitiva que desea obtener (p. 131).

Tabla 2.3

Matriz de la estrategia genérica

\begin{tabular}{l|l|}
\hline \multicolumn{1}{|c|}{ DIFERENCIACIÓN } & \multicolumn{1}{|c|}{ LIDERAZGO EN COSTOS } \\
$\begin{array}{l}\text { Camposol se encuentra realizando una } \\
\text { estrategia de diferenciación ya que } \\
\text { ofrece productos de alta calidad con } \\
\text { alto valor nutritivo, en cantidad y } \\
\text { calidad de nutrientes y adaptando su } \\
\text { oferta a los mercados internacionales, } \\
\text { considerándose a Camposol como una } \\
\text { marca de consumo Premium. }\end{array}$ & $\begin{array}{l}\text { lamposol utiliza una estrategia de } \\
\text { producción, reciáno en costos, debido a que es } \\
\text { especialización y economías de escala, } \\
\text { adicional a esto se encuentra } \\
\text { optimizando sus procesos para reducir } \\
\text { costos implementando nuevas plantas } \\
\text { de procesamiento }\end{array}$ \\
\hline $\begin{array}{l}\text { Camposol no aplica una estrategia de enfoque ya que sus productos van dirigidos } \\
\text { a todos los segmentos de mercado ofreciendo un producto de alta calidad y } \\
\text { características nutritivas importantes. }\end{array}$ \\
\hline
\end{tabular}

Fuente: Porter (1985)

Elaboración Propia 


\subsection{Matriz FODA}

Tabla 2.4

Matriz Foda

\begin{tabular}{|c|c|c|}
\hline & FORTALEZAS - F & DEBILIDADES - D \\
\hline & $\begin{array}{l}\text { Calidad Superior en los } \\
\text { productos(F1) } \\
\text { Producción de productos } \\
\text { orgánicos(F2) } \\
\text { Prueba de nuevos cultivos(F3) } \\
\text { Integración Vertical(F4) } \\
\text { Zona geográfica privilegiada(F5) } \\
\text { Acuerdos Comerciales(F6) } \\
\text { Certificaciones } \\
\text { Internacionales(F7) }\end{array}$ & $\begin{array}{l}\text { Crecimiento desordenado(D1) } \\
\text { Estrategia de Marca no } \\
\text { implementada (D2) } \\
\text { Mano de Obra Escasa en la } \\
\text { Zona(D3) } \\
\text { Concentración } \\
\text { Productos(D4) } \\
\begin{array}{l}\text { Dependencia de la Producción } \\
\text { peruana(D5) }\end{array}\end{array}$ \\
\hline OPORTUNIDADES - O & ESTRATEGIAS - FO & ESTRATEGIAS - DO \\
\hline $\begin{array}{l}\text { TLC }(\mathrm{O} 1) \\
\text { Proyectos de infraestructura(O2) } \\
\text { Crecimiento PBI en } 3.4 \%(\mathrm{O} 3) \\
\text { Ley de promoción agraria(O4) } \\
\text { Auditorias Sociales } \\
\text { ambientales(O5) } \\
\text { Conciencia del consumidor(O6) } \\
\begin{array}{l}\text { Medios electrónicos de } \\
\text { comunicación }(\mathrm{O} 7)\end{array}\end{array}$ & $\begin{array}{l}\text { F1-O1 Desarrollo de mercado } \\
\text { F3 -O1, O2 Diversificación } \\
\text { Relacionada } \\
\text { F1-O1, O6 Creación de estrategia } \\
\text { de marca. } \\
\text { F1, F2-O6, O7 Realizar campañas } \\
\text { de marketing en medios sociales. }\end{array}$ & $\begin{array}{l}\text { D2, O1 Mejorar la penetración } \\
\text { de sus productos actuales. }\end{array}$ \\
\hline AMENAZAS - A & ESTRATEGIAS - FA & ESTRATEGIAS - DA \\
\hline $\begin{array}{l}\text { Inestabilidad Política en el } \\
\text { Perú(A1) } \\
\text { Desaceleración de la economía } \\
\text { China(A2) } \\
\text { Escasez mano de Obra(A3) } \\
\text { Cambios climáticos(A4) } \\
\text { Nuevos Competidores(A5) } \\
\text { Tipo de cambio(A6) } \\
\text { Fenómeno del niño(A7) }\end{array}$ & $\begin{array}{l}\text { F1 -A1 A7 Nuevas área de cultivo } \\
\text { a nivel nacional e internacional } \\
\text { F4-A4 Acuerdos comerciales de } \\
\text { exclusividad }\end{array}$ & $\begin{array}{l}\text { D5-A1 Investigación de } \\
\text { mercados } \\
\text { D1-A4 Realizar campañas de } \\
\text { compromiso y concientización } \\
\text { de los trabajadores } \\
\text { D2-A1 inversiones I+D para la } \\
\text { mitigación de plagas }\end{array}$ \\
\hline
\end{tabular}

Fuente: Bell, D.E., y Kindred, N.(2016), David (2013)

Elaboración Propia

\section{Estrategias FO:}

- Diversificación relacionada: Camposol para no depender de la concentración de productos y disminuir los efectos negativos de una disminución de la demanda, cambios climáticos o baja del precio a nivel 
internacional de sus productos, Camposol debe producir otros productos que le generen rentabilidad y tener una cartera de productos más diversa.

- Desarrollo de mercado: Camposol debe estar en búsqueda de nuevos mercados aun sin explorar para seguir teniendo un potencial de crecimiento aún mayor.

- Creación de estrategia de marca: El éxito a largo plazo para Camposol es que el cliente final reconozca el producto de calidad que ofrece Camposol con lo cual Camposol debe reforzar su marca como una marca Premium de calidad y hacerse conocido con el cliente final a través de la calidad superior de sus productos y campañas de marketing intensivas, que conlleven una preferencia de parte del consumidor por la marca.

- Campañas de Marketing: Para darse a conocer con el cliente final y fortalecer su relación, Camposol deberá diseñar una estrategia de marketing en medios sociales, dando a conocer sus productos, las características y lugares de compra y recibir una retroalimentación del cliente final.

\section{Estrategias FA:}

- Nuevas áreas de cultivo a nivel nacional e internacional: Con el fin de la minimización de riesgos ambientales y políticos Camposol deberá seguir una estrategia de internacionalización con respecto a áreas de cultivos en otros países y la mitigación de riesgos coyunturales del país.

- Acuerdos Comerciales de exclusividad: Para contrarrestar el ingreso de nuevos competidores Camposol deberá formar acuerdos de exclusividad y de relación a largo plazo con los minoristas para asegurar la venta de su producción y la relación a largo plazo de sus productos.

\section{Estrategias DO:}

- Penetración de sus productos: Aprovechar en abarcar la mayor cantidad de minoristas en los países donde ya incursiona para realizar un aumento de la penetración de su cartera de productos y tener una mayor presencia en el cliente final. 


\section{Estrategias DA:}

- Campañas de compromiso y fidelización de trabajadores: Camposol deberá realizar esfuerzos para mejorar la retención del talento humano a través de una campaña de fidelización e identificación con la compañía.

- Investigación de mercados: Realizar investigación para la apertura de nuevos mercados de acuerdo a los gustos y necesidades de los clientes, Según Malhotra (2008) La investigación de mercados mejora la toma de decisiones relacionadas con identificar y solucionar problemas y oportunidades de marketing (p.7).

- Impulsar la inversión en I+D: Camposol deberá seguir invirtiendo en investigación y desarrollo para contrarrestar los posibles efectos de plagas que puedan afectar la cosecha de sus cultivos.

\subsection{Definición y sustentación de la Visión, Misión y Políticas}

Para poder hacer una mejor evaluación de la empresa y plantear estrategias que mejoren sus procesos internos y capacidad es necesario evaluar los aspectos básicos como la visión, misión y las políticas internas de la empresa.

Visión: La Visión de Camposol es ser el proveedor preferido y superior de alimentos saludables y frescos para familias de todo el mundo. La Visión de Camposol define la estrategia a seguir en el futuro brindar un producto y servicio superior, expandirse a través de nuevos mercados siendo el proveedor preferido para los minoristas y los clientes finales ofreciendo productos bajo los mayores estándares de calidad y valor.

Misión: La misión de Camposol es brindar a sus clientes, productos saludables y diferenciados a consumidores de todo el mundo. Esto lo logran través de la excelencia e innovación en sus procesos y el desarrollo de sus colaboradores, generando un impacto positivo en sus stakeholders. La misión de Camposol define su cadena de valor para lograr que los productos lleguen de la mejor manera creando un impacto positivo en todos sus stakeholders. 
Políticas: Las políticas de una empresa se pueden definir de acuerdo a los valores que posee la misma, Camposol posee una serie de valores que van alineadas con su misión, visión y el valor que desean ofrecer al cliente:

- Integridad: Camposol busca que sus colaboradores honren sus compromisos y asuman las consecuencias de sus actos teniendo en cuenta el lado económico, social y ambiental.

- Respeto: Se favorece el buen trato y se valora a sus colaboradores.

- Trabajo en equipo: Camposol fomenta un espacio de trabajo en equipo donde los objetivos organizacionales y de equipo prevalezcan sobre los objetivos personales.

- Austeridad: Camposol se propone ser eficiente a lo largo de toda su cadena de valor, teniendo un buen manejo de sus costos y detectando oportunidades de mejora en reducción de costos.

- Excelencia: Camposol ofrece los más altos estándares de innovación, desempeño y calidad en todas sus áreas y procesos y cumplir con los requisitos del mercado mundial.

David (2013) señala: "Las políticas consisten en directrices, reglas y procedimientos establecidos para apoyar los esfuerzos realizados para alcanzar dichos objetivos" (p.12).

Camposol busca que sus colaboradores trabajen de acuerdo a los valores organizaciones y se esfuercen al máximo en ser eficientes a través del manejo de costos, valorando el trabajo en equipo, la integridad y el respeto desempeñándose de la mejor manera para ofrecer un productor calidad a sus clientes.

\subsection{Definición de los Objetivos Estratégicos de la empresa}

Considerando que Camposol está en búsqueda de un crecimiento en nuevos mercados y el aumento de su penetración se propone los siguientes objetivos estratégicos alineados con su visión.

Objetivo 1: Cotizar en la Bolsa de valores de Nueva York para el año 2020.

Objetivo 2: Incrementar la rentabilidad en un 5\% para el año 2020. 
Objetivo 3: Reducción en costos en un 5\% para el año 2021.

Objetivo 4: Incrementar la penetración de mercado a través de un mayor número de minoristas en $5 \%$.

Objetivo 5: Desarrollar nuevas áreas de cultivos en 1,000 hectáreas a nivel internacional para el 2021.

Objetivo 6: Desarrollar dos centros de maduración de productos en los países destinos para el año 2023.

Objetivo 7: Incrementar en 10\% la inversión en I + D, para el desarrollo de nuevos cultivos y mitigación de plagas para el 2021.

\subsection{Redefinición de las Unidades Estratégicas de Negocio (UEN) o creación de nuevas UEN}

Camposol posee tres UEN entre ellos se encuentran: UEN de Frutas y Verduras, UEN de Mariscos (Marinasol) y la UEN de Comercio, de acuerdo al manejo y enfoque que da Camposol a sus líneas de negocio se considera que las tres UEN cumplen su objetivo con lo cual las UEN se mantienen para la empresa Camposol.

\subsection{Propuesta y sustentación de estrategias en el ambiente Global, Corporativas de Negocios y Funcionales}

Estrategias globales: Camposol aplica una estrategia internacional, no tiene presión por costos ni adaptación local, centraliza las funcionas en la casa Matriz, en Perú, donde realiza gran parte de su cadena de valor y envía sus productos sin embargo estudia las características y necesidades de los mercados extranjeros para ofrecer las características preferidas por sus clientes finales

\section{Estrategias corporativas}

- Alianzas estratégicas: Camposol posee diversas alianzas estratégicas con minoristas internacionales asegurando altos volúmenes de compra y un precio establecido durante toda la campaña de su producción, gracias a esto 
Walmart tuvo uno de sus mejores años en rendimientos de la palta con Camposol.

- Integración vertical hacia delante: Como una estrategia Camposol debería invertir en centros de maduración para sus productos con el fin de no depender de terceros y poder llegar a un mayor número de minoristas que no cuentan con centros de maduración propios y aumentar su penetración.

- Diversificación relacionada: Camposol debe seguir investigando en nuevas variedad y cultivos para así ampliar su cartera de productos y no depender de los rendimientos de pocos productos.

Estrategias de Negocio: Camposol aplica una estrategia de liderazgo en costos, siendo eficiente en sus procesos para la reducción de costos, además al tener una producción de altos volúmenes tiene economías de escala, sin embargo, también aplica una estrategia de diferenciación, ya que ofrece productos de alta calidad, con un alto valor en nutrientes, a su vez que la integración vertical que posee ayuda a otorgar sus productos de la mejor manera.

\section{Estrategias funcionales}

\section{- Recursos Humanos}

Se propone realizar estrategias de retención mejoramiento del clima laboral para retener el talento humano, adicional a ello se sugiere una capacitación constante a sus colaboradores, permitiendo que los procesos internos se ejecuten de la mejor manera, por último, realizar evaluaciones de desempeño periódicas con el fin de mantener al personal calificado para la compañía y analizar las oportunidades de mejora de sus colaboradores.

\section{- Finanzas}

Camposol a través de un mayor desarrollo de mercado y penetración de sus productos deberá incrementar los ingresos, posterior a ello la reducción de costos de mano obra a través construcción de los complejos habitacionales cerca de los campos de cultivos, significará un impacto positivo en la reducción de costos de transporte, lo cual significará un aumento en la rentabilidad neta de la compañía. 


\section{- Operaciones}

Aumentar la inversión en I+D para la generación de nuevos cultivos y variedades y la constante investigación en investigación para el control de plagas naturales.

\section{- Marketing}

Camposol debe seguir reforzando su marca, dándose a conocer al cliente final, a través de medios convencionales y no convencionales y con publicidad y merchandising en el punto de venta para que los clientes finales puedan asociar sus productos y la calidad que poseen y ellos mismo s pidan Camposol Según Kotler y Armstrong (2013) el productor ajusta la estrategia de marketing para cada mercado, eso ocasiona mayores costos, pero produce una mayor participación de mercado y rendimiento (p. 467). 


\section{CAPÍTULO III: IMPLEMENTACIÓN ESTRATÉGICA}

\subsection{Evaluación del rediseño o no rediseño de la estructura organizacional de la empresa(Sustento)}

Según Sverdlik, Williams, Dubrin y Sisk (1991) La estructura es la forma en que sus componentes están diseñados e interrelacionados (p. 213).

Figura 3.1

Estructura organizacional de Camposol

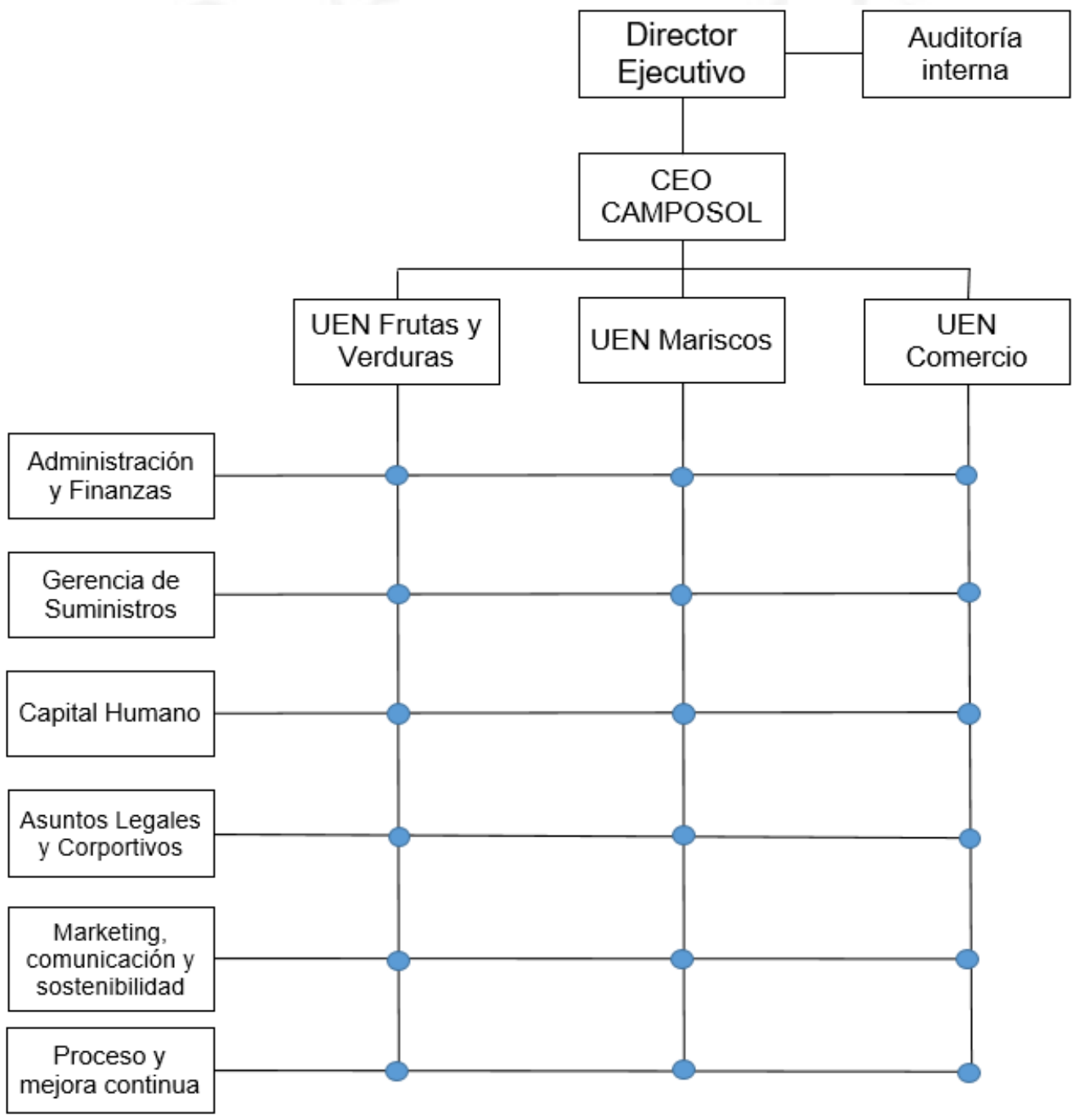

Elaboración propia

David (2013) señala: "Una estructura matricial es el más completo de los diseños, pues depende de los flujos verticales y horizontales de autoridad y comunicación” (p. 227). 
Se propone modificar el rediseño de la estructura para favorecer la comunicación, trabajo en equipo y coordinación de las áreas internas de soporte para así reducir los problemas de comunicación y lograr una mayor eficiencia en sus procesos internos y satisfacer las necesidades del cliente, se mantendrá las tres UEN claves para la empresa y se implantará una estructura matricial facilitando la comunicación transversal entre las áreas funcionales y las tres UEN.

\subsection{Propuesta de cambios para mejorar la implementación de estrategias en la empresa}

Para mejorar la implementación de las estrategias propuestas para Camposol en primer lugar se deberá realizar una reestructuración en la estructura organizacional con el fin de que las áreas internas posean una mayor comunicación y eficiencia transversales hacia todas las UEN, en segundo lugar para favorecer la oferta de nuevos productos se deberá incentivar una mayor inversión en I+D para la prueba de nuevos cultivo y variedades y contrarrestar posibles efectos de plagas y entes contaminantes, en tercer lugar se plantea el desarrollo de nuevos mercados con el fin de aumentar el alcance internacional y tener mayor oportunidad de crecimiento, en cuarto lugar, el desarrollo de cultivos a nivel internacional y por último desarrollar una estrategia de integración vertical hacia adelante creando centros de maduración propios y no depender de terceros aumentado su cuota de mercado. 


\section{CAPÍTULO IV: CONTROL ESTRATÉGICO}

\subsection{Diseño de un Mapa Estratégico de Control para la empresa}

Según Kaplan y Norton, el mapa estratégico es una representación gráfica de cómo la empresa piensa desarrollar su estrategia (Kaplan y Norton, 2009, p. 79).

Figura 4.1

Mapa estratégico de Camposol

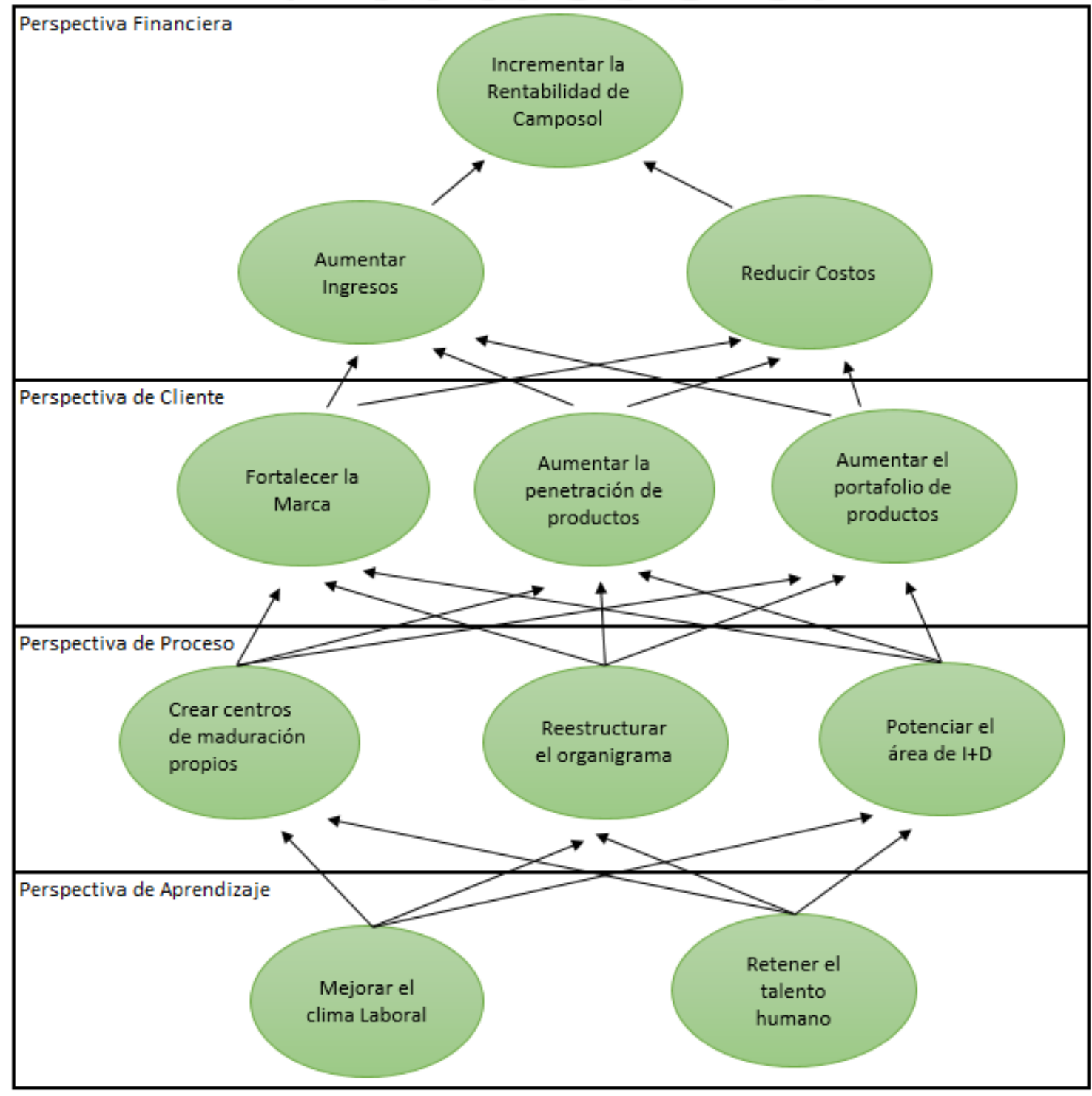

Fuente: Kaplan y Norton (2009)

Elaboración propia 


\subsection{Desarrollo de un Cuadro de Mando Integral con un mínimo de diez índices de gestión}

En base al mapa estratégico propuesto en el punto 4.1, se plantean indicadores para la aseguración del cumplimiento de las metas propuestas.

David (2013) señala: "El cuadro de mando integral es una técnica para la evaluación y control de estrategias" (p. 135).

Tabla 4.1

Cuadro de mando integral

\begin{tabular}{|c|c|c|c|}
\hline PERSPECTIVA & OBJETIVOS BSC & PORCENTAJE & INDICADOR BSC \\
\hline \multirow{3}{*}{ FINANCIERA } & Aumentar las Utilidades & $5 \%$ & $\begin{array}{l}\text { ROE }- \text { Rentabilidad } \\
\text { sobre el patrimonio }\end{array}$ \\
\hline & Aumentar los Ingresos & $5 \%$ & Ingresos Anuales \\
\hline & Reducir los costos & $10 \%$ & Costos Anuales \\
\hline \multirow{3}{*}{ CLIENTES } & $\begin{array}{l}\text { Aumentar el } \\
\text { reconocimiento de la } \\
\text { Marca }\end{array}$ & $>5$ & $\begin{array}{l}\text { Participación en ferias } \\
\text { internacionales }\end{array}$ \\
\hline & $\begin{array}{l}\text { Captación de Nuevos } \\
\text { clientes }\end{array}$ & $>3$ & $\begin{array}{l}\text { Número de nuevos } \\
\text { clientes }\end{array}$ \\
\hline & $\begin{array}{l}\text { Desarrollar nuevos } \\
\text { productos }\end{array}$ & $>2$ & $\begin{array}{l}\text { Número de productos } \\
\text { nuevos }\end{array}$ \\
\hline \multirow{3}{*}{ PROCESOS } & $\begin{array}{l}\text { Desarrollar centros de } \\
\text { maduración propios }\end{array}$ & $>2$ & $\begin{array}{l}\text { Cantidad de centros de } \\
\text { maduración abiertos }\end{array}$ \\
\hline & $\begin{array}{l}\text { Fortalecer la } \\
\text { comunicación interna }\end{array}$ & $>2$ & $\begin{array}{l}\text { Eventos de integración } \\
\text { entre las áreas internas y } \\
\text { los jefes de cada área }\end{array}$ \\
\hline & $\begin{array}{l}\text { Aumentar la inversión } \\
\text { en I+D }\end{array}$ & $10 \%$ & Monto invertido en I + D \\
\hline \multirow{2}{*}{ APRENDIZAJE } & $\begin{array}{l}\text { Realizar evaluación de } \\
\text { desempeño }\end{array}$ & $85 \%$ & $\begin{array}{l}\text { Rendimiento del personal } \\
\text { en su puesto }\end{array}$ \\
\hline & $\begin{array}{l}\text { Capacitar y desarrollar } \\
\text { personal }\end{array}$ & $>10$ & $\begin{array}{l}\text { Número } \\
\text { capacitaciones }\end{array}$ \\
\hline
\end{tabular}

Fuente: Kaplan y Norton (2009)

Elaboración propia 


\section{CONCLUSIONES}

Camposol ha experimentado un crecimiento rápido debido al éxito de nuevos cultivos y al crecimiento de la demanda por países extranjeros, Camposol tuvo que reformular sus procesos internos para poder aprovechar las nuevas oportunidades que se le presentaban.

En los últimos años Camposol ha estado definiendo su estrategia de cara para el futuro buscando una diferenciación en su producto con respecto a otras marcas y en un proceso de internacionalización de apertura de nuevos mercados.

El estudio de las variables internas y externas desarrolladas en el presente trabajo, permiten plantear el desarrollo de nuevas estrategias enfocadas al crecimiento y expansión de Camposol a nivel internacional, Camposol posee aún una gran oportunidad de crecimiento y consolidación siendo la empresa peruana líder en el sector agroexportador y consolidándose como uno de los grandes referentes a nivel mundial siendo una marca Premium preferida por sus clientes internacionales. 


\section{RECOMENDACIONES}

- Camposol debería seguir impulsando su área de investigación y desarrollo con el fin de contar con nuevos cultivos dentro de su portafolio de productos y ofrecer una cartera de productos más amplia a sus clientes y no depender en gran medida de los rendimientos de unos pocos productos.

- Camposol debería mejorar el proceso de comunicación interna y vinculación de las áreas internas con el fin de que los pedidos no sufran inconvenientes para el cliente final.

- $\quad$ Siguiendo la estrategia de Camposol de poseer una integración vertical, el siguiente paso para Camposol sería, abrir centros de maduración propios en los mercados destinos y tener una menor dependencia de terceros y tener una venta directa a todos los minoristas.

- Camposol deberá seguir trabajando en su marca, a través de diversas campañas deberá reforzar el concepto de marca Premium y que los clientes finales reconozcan y pidan el producto.

- Camposol deberá invertir en nuevas áreas de cultivos en distintos países con el fin de reducir los riesgos procedentes de una determinada zona geográfica. 


\section{REFERENCIAS}

Banco Mundial (2019). Crecimiento del PIB (\% Anual). Recuperado de https://datos.bancomundial.org/indicator/NY.GDP.MKTP.KD.ZG?end=2018\&1 ocations=PE\&start $=1998 \&$ view $=$ chart

Bell, D.E., y Kindred, N.(2016). Camposol (caso 518-S10). Recuperado del sitio de internet de Universidad Harvard, Escuela de Negocios: https://www.harvard.edu/

Chiavenato, I. y Sapiro, A. (2011) Planeación estratégica (2. ${ }^{a}$ ed.) México D.F.: Mc Graw Hill.

El Comercio (2018) La corrupción, el principal problema del Perú. Recuperado de https://elcomercio.pe/politica/corrupcion-principal-problema-peru-noticia$\underline{513999}$

David, Fred R. (2013) Administración estratégica (14. ${ }^{a}$ ed.). México D.F.: Pearson.

Diario el Peruano (2019) Gobierno priorizará 15 grandes proyectos de irrigación en el país. Recuperado de https://www.elperuano.pe/noticia-gobierno-priorizara-15grandes-proyectos-irrigacion-el-pais-75445.aspx

Hitt, M., Ireland, R. y Hoskisson, R. (2015). Administración Estratégica. (11. $\left.{ }^{\mathrm{a}} \mathrm{ed}.\right)$. México D.F.: Cengage.

Kaplan, R. S. y Norton, D. P. (2009). Cómo utilizar el cuadro de mando integral: Para implantar y gestionar su estrategia (2. ed.). Barcelona: Ediciones Gestión 2000.

Kotler, P. y Armstrong, G. (2013). Fundamentos de Marketing (11. ${ }^{\mathrm{a}}$ ed.) México D.F.: Pearson.

Ley N. ${ }^{\circ} 27360$, Ley que aprueba normas de promoción del Sector Agrario. (11 de setiembre de 2002). Recuperado del sitio de internet del Congreso: http://www2.congreso.gob.pe/sicr/cendocbib/con4_uibd.nsf/5C947E120537341 B05257B7A004B13E5/\$FILE/27360.pdf

Luna, A. (2014). Administración estratégica. México D.F.: Grupo editorial Patria.

Malhotra, N. (2008) Investigación de mercados (5. ${ }^{\mathrm{a}}$ ed.) México D.F.: Pearson.

Ministerio de Economía y finanzas. (2019). Acuerdos vigentes. Recuperado de: https://www.mef.gob.pe/es/economia-internacional/acerca-de-aspectoscomerciales/acuerdos-vigentes

Ministerio de Economía y Finanzas (2019). Informe de actualización de proyecciones macroeconómicas 2019 - 2022. Recuperado del sitio de:

https://www.mef.gob.pe/contenidos/pol_econ/marco_macro/IAPM_2019_2022. pdf 
Naciones Unidas. (2019). Cambio Climático. Recuperado de:

https://www.un.org/es/sections/issues-depth/climate-change/index.html

Osterwalder, A. y Pigneur, Y. (2010). Generación de modelos de negocio. España: Deusto.

Peteraf, T. y Strickland, G. (2012). Administración estratégica (18. ${ }^{a}$ ed.) México D.F.: Mc Graw Hill.

Porter M.E. (1985). Competitive Advantage.: The free press.

SIICEX. (2019a). Empresas exportadoras de arándanos. Recuperado de http://www.siicex.gob.pe/siicex/portal5ES.asp?_portletid_=SFichaProductoEmp $\underline{\text { resaX\&_page }=216.17100 \& \text { scriptdo }=c c \_f p \_e m p r e s a x \& \text { session_pTarifa }=8104}$ 00000\&colOrder $=3 \#$ anclafecha

SIICEX. (2019b). Empresas exportadoras de espárragos. Recuperado de http://www.siicex.gob.pe/siicex/portal5ES.asp?_page_=172.17100\&_portletid $=$ sfichaproductoinit\&scriptdo $=\mathrm{cc} \_$fp_init\&pproducto $=\% 2085 \% 20 \&$ pnomproduc $\underline{\text { to }=\% 20 \mathrm{Esp} \% \mathrm{E} 1 \mathrm{rrago}}$

SIICEX. (2019c). Empresas exportadoras de aguacates. Recuperado de http://www.siicex.gob.pe/siicex/portal5ES.asp?_page_=172.17100\&_portletid $=$ sfichaproductoinit\&scriptdo $=c c$ fp_init\&pproducto $=\% 20145 \% 20 \&$ pnomprod $\underline{\text { ucto }=\% 20 \mathrm{Palta}}$

Sverdlik, M., Williams, J., Dubrin, A. y Sisk, H. (1991). Administración y organización (2. ${ }^{a}$ ed.). Miami: Harper Collins. 


\section{BIBLIOGRAFÍA}

Camposol. (s.f). Our story. Recuperado de https://www.camposol.com.pe

Camposol (2018). Informe de Sostenibilidad 2017. Recuperado de http://camposol.com.pe/wpcontent/uploads/2019/02/camposol_sustainability_report_2017.pdf

Camposol (2018). Anual Report 2017. Recuperado de http://camposol.com.pe/wpcontent/uploads/2019/02/camposol_annual_report_2017.pdf

Marinasol (s.f.). Instalaciones. Recuperado de:

https://www.marinasol.com.pe/es/index.php

Minagri (2016) El arándano en el Perú y el mundo. Recuperado de:

http://agroaldia.minagri.gob.pe/biblioteca/download/pdf/tematicas/ftaxonomia_plantas/f01-cultivo/el_arandano.pdf 
ANEXOS 


\section{Anexo 1: Principales países exportadores de Arándanos}

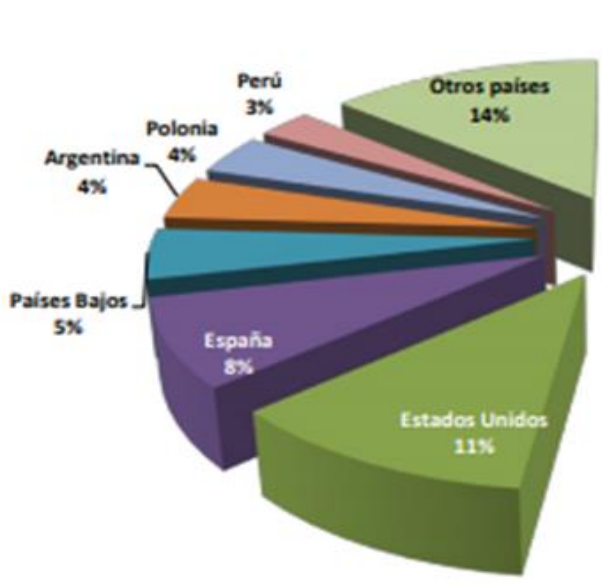

Fuente: ITC-Trade Map 2016

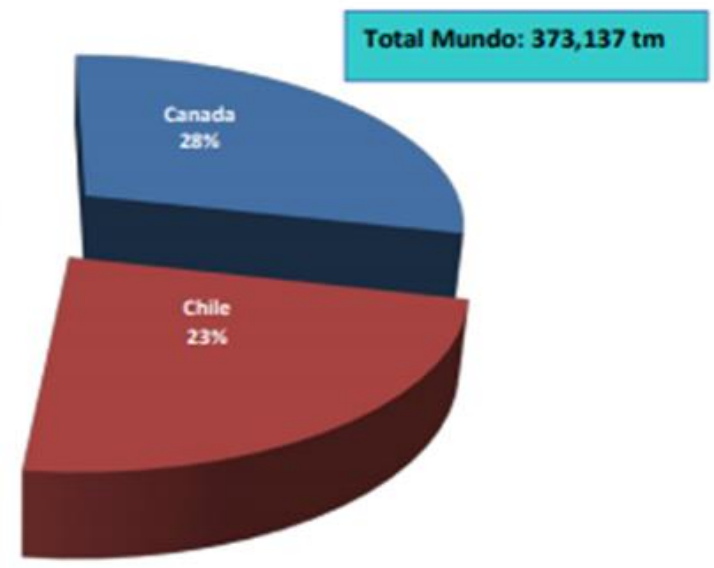

Elaboración: DGPA-DEEIA

Fuente: Minagri (2016) 


\section{Anexo 2: Ventana de producción de Arándanos por países}

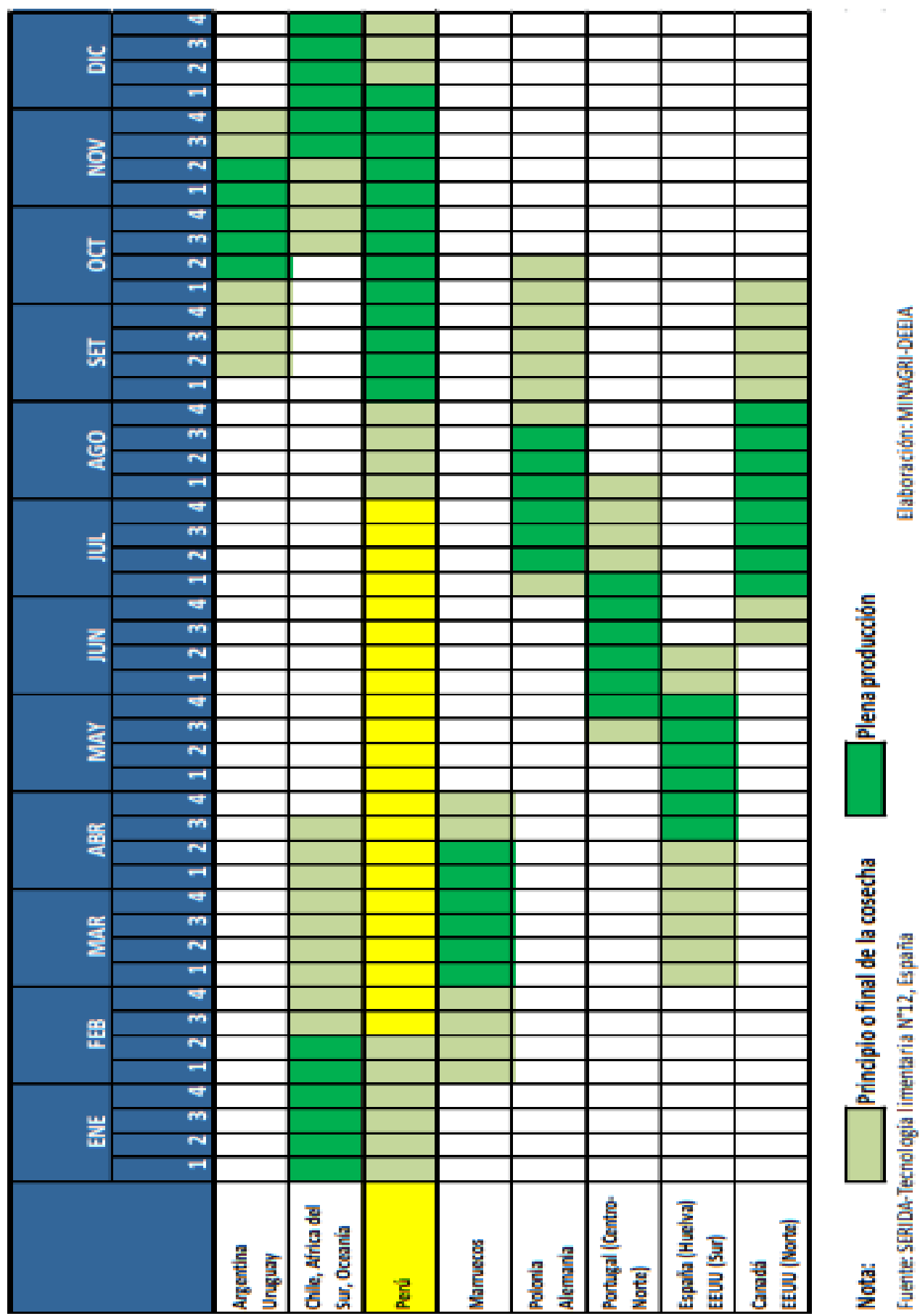

Fuente: Minagri (2016) 